\title{
Discusiones 8
}

\section{Dilemas morales y Derecho. Una crítica a David Martínez}

Guillermo Lariguet**

*Agradezco a Eduardo Rivera López por sus críticas a mi trabajo

** Conicet, Argentina.

1 Publicado originariamente en Philosophical Review, 70. Luego recogido en Lemmon, E.J: "Moral Dilemmas", en Gowans.C.D (Ed), Moral Dilemmas, Oxford University Press, New York, 1987, pp. 101-114.

\section{Introducción}

Durante mucho tiempo la cuestión de los dilemas morales estuvo sepultada bajo un manto de sal. Fue entre otros, el célebre artículo "Moral Dilemmas", publicado por Lemmon en $1962^{1}$, el que reavivó la discusión filosófica, especialmente en el mundo anglosajón.

Las explicaciones de porqué existió este manto de sal y de porqué duró tanto tiempo requiere de un ensayo independiente del que voy a ofrecer aquí. Cabe subrayar que este manto de sal, con pocas 
excepciones, ha perdurado mucho más tiempo en el campo del derecho que en el de la filosofía moral y política y la escasa atención que los filósofos del derecho han prodigado a la cuestión, así lo atestigua.

Alguna vez Carlos Rosenkrantz me ha dicho que si uno fuera capaz de despejar la cuestión de los dilemas morales, despejaría, o desataría si se prefiere, los principales nudos sobre los que los filósofos del derecho forcejean. ${ }^{2}$

Ahora bien, difícilmente pueda negarse que los filósofos estamos habituados a enfrentarnos a eventuales aporías al finalizar nuestro trabajo sobre un problema. La aporía no es más ni menos que esa "dificultad de pasar". En un momento determinado del examen filosófico de un problema, el camino se ve interrumpido por un abismo. ¿Cómo pasarlo?

En “Dilemas Morales y Derecho” David Martínez nos propone un camino que sea capaz de generar un puente, una posibilidad de paso. Martínez admite desde el inicio de su trabajo que la tarea no es sencilla pues, como él correctamente afirma, "el de los dilemas morales es sin ninguna duda uno de los temas más interesantes y al tiempo problemáticos del ámbito de la filosofía moral"3. En su tratamiento de la cuestión, Martínez da sobradas muestras de porqué su afirmación, relativa al carácter difícilmente tratable de los dilemas morales, es válida.

Martínez está interesado en mostrar la eventual relevancia jurídica que puedan tener los dilemas morales en el campo del derecho. A este

\footnotetext{
${ }^{2}$ Aclaro que el uso de cursivas en pasajes propios o citados, de aquí en adelante, es de mi autoría.

${ }^{3}$ Las citas entrecomilladas las tomo de la versión manuscrita del trabajo de David Martínez del que dispongo para escribir mi crítica. Dado que muy probablemente la numeración de esta versión no coincidirá con la edición en Discusiones, no me tomaré el trabajo de citar páginas que el lector no encontrará en esta publicación. Los pasajes son fácilmente reconocibles en el texto de Martínez y pienso que el lector los identificará sin dificultades en la presente edición. Por tal motivo, aquí sólo irán indicados bajo comillas sin citación de páginas.
} 
respecto, su pretensión principal es la de ofrecer una clarificación de los conceptos en juego y sus relaciones. En forma más limitada, sin embargo, intenta defender una propuesta normativa acerca de cómo 'resolver' situaciones de dilema moral que puedan tener relevancia para el derecho. Vale la pena aclarar que esta propuesta -a la que habré de referirme luegoes matizada por él en cuanto al contexto jurídico. Según Martínez, esto es así porque aun si el sistema jurídico puede remitir en algunos casos al discurso moral ${ }^{4}$ y en éste se puede plantear una situación de dilema, que será entonces jurídicamente relevante, "no necesariamente parecerá acertado resolverlo del mismo modo, debido a ciertas características importantes de los sistemas jurídicos".

Quiero desde ya señalar lo que considero virtudes del trabajo de Martínez. En mi opinión es un trabajo que, además de ser sumamente interesante, tiene la ventaja de: i) ser claro en lo conceptual; ii) ofrecer distinciones aceptables; iii) en general, estar correctamente escrito.

No obstante lo anterior, el trabajo presenta a mi criterio dos desventajas que a la postre, espero, resultarán evidentes y que por ahora solo esbozaré a grandes rasgos. La primera, que atañe a su pretensión principal de clarificación conceptual, me parece que no proyecta una luz nueva sobre la cuestión de los dilemas morales; con otras palabras, no se advierte en su trabajo cuáles serían las ganancias conceptuales de esta clarificación que él propugna; clarificación que ya resulta conocida ampliamente por cualquiera que tenga mediana cultura filosófica. Estimo, además, que su enfoque es innecesariamente cauto y esto, lejos de ser una fortaleza de su trabajo, revela su vulnerabilidad. Posiblemente esto se vea mejor si logro mostrar, entre otras cosas, que Martínez no logra distinguir adecuadamente los conflictos constitucionales ordinarios o los conflictos normativos simpliciter de los dilemas morales, desarrollando las consecuencias más relevantes para el derecho.

\footnotetext{
${ }^{4}$ Además Martínez supone que en general, en esta hipótesis, el material jurídico padece algún tipo de "indeterminación".
} 
La segunda pretensión, que tiene que ver con su propuesta normativa, me parece la parte más atractiva del trabajo de Martínez. Con todo, entiendo que la fundamentación que suministra Martínez de su tesis normativa no es claramente consistente con segmentos relevantes de su trabajo y, además, es lisa y llanamente inviable. No obstante, la tesis normativa que él defiende ofrece elementos implícitos sugestivos que desarrollados bajo su mejor aspecto pueden volver no solo consistente su trabajo sino hacerlo más vigoroso. Pero para ello resulta menester que el producto de la elucidación filosófica que propondré sea la sustitución de su tesis normativa por otra de mayores posibilidades.

Dado que mis afirmaciones no pretenden ser gratuitas, pues soy consciente de que me estoy ocupando de un trabajo importante de un colega riguroso, voy a esforzarme por justificar lo que digo.

Estructuraré este artículo en tres partes. Las primeras dos partes presupondrán una faena doble: por un lado, criticar aspectos que considero deficientes del planteo de Martínez, por el otro, sugerir constructivamente vías para plantear de modo más fecundo la cuestión de los dilemas morales y su relevancia jurídica. De estas dos partes, la primera se dedicará a examinar la pretensión de clarificación conceptual de Martínez, mientras que la segunda será dedicada a su propuesta normativa. En la tercera y última parte ofreceré una recapitulación de algunas de las ideas tratadas en el presente trabajo que me parece deben subrayarse.

\section{Parte crítica}

\section{La pretensión de clarificación conceptual de Martínez}

David Martínez propone una tarea de clarificación conceptual de la noción de dilema moral y su eventual relevancia para el derecho.

Si bien el intento de Martínez es valioso, pues construye una base para la discusión filosófica, creo que su trabajo tiene dos defectos centrales: el primero es que, como espero mostrar, no logra deslindar de 
manera precisa la categoría de los conflictos normativos y/o constitucionales de los dilemas morales; el segundo es que su caracterización "estipulativa" de los dilemas morales resulta insatisfactoria a la hora de tratar con la compleja fenomenología de los dilemas morales. Pronto me ocuparé de estas dos cuestiones, pero antes de ello quiero precisar qué es lo que Martínez incluye y excluye de su análisis filosófico.

\section{Lo que Martínez deja fuera y lo que Martínez deja dentro}

De antemano, Martínez aclara que su pretensión es modesta y limitada. En buena medida su aclaración parece corroborarse en las restricciones que él impone a su trabajo. Él no pretende realizar un "análisis detallado ni de los conflictos jurídicos ni de los dilemas morales" sino, más bien, examinar una situación específica, así como sus consecuencias, en la que "puede ocurrir que el sistema jurídico, para dar respuesta a un caso, de algún modo remita al ámbito del discurso moral y en éste se plantee una situación de dilema".

Pienso que, dado que el tema de los dilemas morales es sumamente complicado como Martínez mismo reconoce, la restricción que él plantea al inicio de su trabajo es inadecuada. No impugno la legitimidad de establecer límites y suscribo su idea de que no puede pretenderse que en un trabajo se de cuenta en forma detallada y exhaustiva de la cuestión.

Sin embargo, dado también que la cuestión de los dilemas morales tiene una relevancia para la discusión filosófico-jurídica que todavía hay que mostrar, la restricción que él impone me parece excesiva e incluso conspirativa con el deseo de mostrar, a la postre, la relevancia jurídica de los dilemas morales, cuestión en la que él se detiene. Sobre todo esto es así en cuanto se admite que una teoría filosófica es aceptable en cuanto ayuda a iluminar mejor el comportamiento de ciertos aspectos de la práctica.

En cualquier caso, Martínez deja fuera de su trabajo las siguientes tres hipótesis:

i) Situaciones que de algún modo pueden verse como 
conflictivas o dilemáticas y que afectan simultáneamente a los ámbitos moral y jurídico.

ii) Situaciones que, siendo conflictivas en el ámbito jurídico, no lo son en el ámbito moral y viceversa.

iii) Situaciones en que diversos sistemas morales alternativos ofrezcan soluciones divergentes e incompatibles, puesto que no constituyen un verdadero dilema ya que la noción de 'dilema' manejada es relativa a un único sistema normativo.

Como ya indiqué, Martínez solo deja dentro de su trabajo situaciones de controversia jurídica que remitan de un modo u otro al discurso moral, el cual puede hallarse indeterminado. Aunque algo diré sobre esta idea de remisión y sobre la relación entre dilemas e indeterminación ahora deseo efectuar las siguientes observaciones.

En primer lugar, creo que no se encuentra justificado, salvo por la trivial razón de espacio de un paper, que Martínez deje fuera de su tratamiento "situaciones" como las descriptas en i) a iii) pues deja escapar así los aspectos salientes de la fenomenología de los dilemas morales. De manera similar a Lemmon, mi tesis es que la expresión "dilemas morales" es solo un rótulo para englobar situaciones de conflicto moral de diversos grados de complejidad. Esto mismo ya acarrea un problema: quizás, el uso de un 'universal' para dar cuenta de situaciones que quizás solo comparten ciertos parecidos familiares no esté suficientemente justificado; dicho de otra manera, es probable que la fenomenología de los dilemas morales sea demasiado compleja, compuesta de situaciones distintas no fácilmente reducibles a una fórmula estipulativa. Así, el camino que sugiero, indica que un desafío para los filósofos es que logremos distinguir, para el caso del derecho, las distintas y más relevantes situaciones dilemáticas y no encasillarnos en una como hace Martínez. Con lo dicho lo que estoy tratando de señalar es que Martínez ha excluido injustificadamente otras situaciones posibles de dilema moral con relevancia jurídica. En este sentido soy de la opinión que Martínez deja escapar las situaciones más ricas y llamativas de los dilemas morales. 
En gran medida esta exclusión tiene una explicación, sobre la que luego volveré: Martínez se fía demasiado de la estipulación como recurso filosófico. Adviértase que él deja fuera una situación como la iii) por no constituir un verdadero dilema en el sentido en que no se adecua a la noción manejada por él. Pienso que el trato puramente definicional de problemas filosóficos complicados no despeja nada sino más bien congela la discusión.

A tal punto llega el afán estipulativo de Martínez que en su trabajo, más adelante, dice cosas como la siguiente: "no es el propósito del presente trabajo decir si en la práctica (en lo que llamaríamos "el mundo real") estas situaciones son posibles o si por el contrario nunca se manifiestan, o cuáles serían ejemplos concretos de situaciones de dilema...".

Entiendo que se puede indagar en las relaciones internas de los conceptos pero la pregunta por su relación con el mundo sensible -para usar una expresión acuñada por la filosofía clásica- es relevante a menos que los conceptos morales y/o jurídicos sean confinados a la Intermundia de Epicuro. Esto es, los conceptos que interesan al ético o al jurista tienen que ver con el mundo empírico, independientemente de cómo se explique este "tienen que ver" si, por ejemplo, bajo una interpretación kantiana (categorías que hacen inteligible fenómenos determinados) o bajo una interpretación hegeliana (donde los conceptos en cierto momento del movimiento del "espíritu" se identifican con su objeto).

Pero es que, además, adviértase que lo que Martínez deja fuera tiene que ver con "situaciones", con "ejemplos", de conflicto o dilema. La cuestión no es trivial por razones de relevancia conceptual porque, si bien es aceptable pensar que hay conflictos "abstractos" de valores (como luego Martínez manifiesta) $)^{5}$ los dilemas morales, muy especialmente, tienen

${ }^{5}$ Por ejemplo, en términos de Hart, entre el valor "justicia" y el valor "bien general". Hart, en la misma vena que Berlin, considera que los conflictos entre valores pueden ser irresolubles, pues los valores pueden ser "irreconciliables" y "radicalmente diferentes". En estos conflictos está presente la idea de "sacrificio"; por ejemplo, diría Hart, si se admite la retroactividad de 
que ver con situaciones concretas, ${ }^{6}$ esto es, con situaciones que suscitan aquello que Kant vio problemático en la Crítica del Juicio: la cuestión de la "facultad de juzgar particulares".

Sea como fuere, Martínez excluye del trabajo tres tipos de situaciones sumamente instructivas ${ }^{7}$ de cara a dar cuenta de la relevancia que para el derecho tienen -o pueden tener- los dilemas morales.

Así, i) muestra nada más ni nada menos que los posibles conflictos entre obligaciones morales y jurídicas que constituyen un clásico ejemplo de las contiendas entre iusnaturalistas y iuspositivistas; descarta también ii) que es una vía promisoria para hacer una distinción, poco frecuente entre los filósofos del derecho, entre "dilemas morales" (relativos a un sistema moral) y "dilemas jurídicos" (relativos a un sistema jurídico). Varios filósofos, incluso, tratan como "dilemas morales" lo que muy fácilmente podría verse como "dilema jurídico", cuestión ésta que no es baladí por sus consecuencias para la perenne discusión acerca de las relaciones que quepa establecer entre derecho y moral. Por ejemplo, creo que cuando Atienza ${ }^{8}$ trata casos como el del "insumiso penal" donde el juez tiene que enfrentarse al dilema de si aplica una norma penal o valores más sustantivos del tipo encarnado por principios constitucionales, el catedrático de Alicante subestima esta distinción y por ello trata como dilemas morales y como situación que se encuadra en i) a lo que uno

una ley penal para enjuiciar acciones de los nazis que "ahora" se reputan como "delitos" habrá que ser conscientes de que se "hiere" o "sacrifica" el principio de "legalidad" en aras de satisfacer un valor moral de "justicia". Ver Hart, H.L.A: El Concepto de Derecho, Traducción de Genaro Carrió, Abeledo Perrot, Bs. As., 1992, pp.206; 227;261. Sobre el enfoque de Berlin véase mi trabajo -de próxima aparición en la Revista de la Facultad de Derecho de la Universidad del Externado de Colombia- titulado "Pluralismo, Conflicto Trágico de Valores y Diseño Institucional. En torno a algunas ideas de Isaiah Berlin".

${ }^{6}$ Le agradezco a Fernando Atria haberme persuadido de la necesidad de enfatizar en esta cuestión.

${ }^{7}$ No diría que la que Martínez enfoca no lo sea.

${ }^{8}$ Ver Atienza, Manuel: Tras la Justicia. Una introducción al Derecho y al Razonamiento Jurídico, Ariel, Barcelona, 1993, Cap. V. 
podría incluir en ii). Pero no es lo mismo un caso como el descrito por i) donde el juez tenga, qua funcionario institucional, una obligación jurídica, por ejemplo de torturar gente sospechada de conductas consideradas delitos por el régimen jurídico de turno, que esté en conflicto con su obligación moral de no torturar, que casos como los planteados por ii). En i) hay problemas específicos que aquí no se pueden tratar y que se encuentran entrelazados con cuestiones tales como si el razonamiento práctico es unitario o fragmentado, si hay algo así como una obligación jurídica discernible de una moral, si ambas son comparables, etc. Pero ii) deja abierta la interesante posibilidad de ver que los jueces, $\mathrm{u}$ otras autoridades normativas, pueden enfrentarse a situaciones de genuinos dilemas jurídicos donde las pretensiones de ambas partes cuentan con protección constitucional, cuestión esta última, típica de los llamados "conflictos constitucionales", que es precisamente foco del interés central de Martínez. Por ejemplo, Paulette Dieterlen ha sometido a escrutinio filosófico situaciones donde ciertas comunidades indígenas expulsan a aquellos miembros que practican una religión distinta a la profesada por la comunidad. Según Dieterlen, la Comisión Nacional de Derechos Humanos de México está enfrentada a un dilema porque las pretensiones, tanto de los que expulsan como la de los expulsados, están resguardadas por la Constitución Mexicana; por ejemplo, de un lado, se reconoce la existencia de comunidades y el respeto al multiculturalismo; del otro lado, se reconoce la libertad de cultos. ${ }^{9}$

Desgraciadamente también Martínez quita del medio el tratamiento de iii) por no constituir un verdadero dilema. Pero no creo que esto sea plausible siempre. Perfectamente se puede conjeturar la existencia de un caso susceptible de ser resuelto con normas que expresen valores incompatibles y esto podría ser el germen de un dilema moral genuino.

\footnotetext{
${ }_{9}^{9}$ Dieterlen, Paulette: "Sobre el principio de rectificación de injusticias", en Dilemas éticos, Mark Platts (compilador), Fondo de Cultura Económica, México, 2000, p. 165.
} 
Lo que digo puede mostrarse con dos ejemplos extraídos de la literatura trágica: La Orestíada y Hamlet.

Así, por un lado, se puede pensar que la Trilogía de la Orestíada de Esquilo, esto es, Agamenón, Las Coéforas y las Euménides, ha sido interpretada por los especialistas como la expresión de la conflagración entre valores pertenecientes a sistemas normativos diversos e incompatibles: por un lado entre los nuevos valores de lo democrático y racional ejemplificados en Apolo, por otro lado en lo tradicional, filial, afectivo, femenino, expresado por la venganza de las Furias. ${ }^{10}$

Por otro lado, cuando Hamlet señala "en mi corazón había una suerte de lucha”, se podría decir que en su alma atormentada subyacen dos sistemas morales diferentes y antagónicos que, a diferencia de lo observado por Martínez, son manifestación de un genuino dilema moral: por una parte, la moral de la venganza, la vieja moral (digamos: premoderna, medieval y guerrera) de la honra y la revancha, por la otra, la moral -al estilo de Maquiavelo-, que resulte útil para el Estado ${ }^{11}$.

A lo ya dicho hay que agregar dos cosas más. Primero, aun si es cierto que un dilema se relativiza a un sistema normativo, en este caso dado los intereses de Martínez a uno "moral”, esto es distinto de mostrar que los valores o las pretensiones de ese sistema sean reconstruidas desde distintas teorías o interpretaciones morales. Segundo, si se admite que el sistema en cuestión resulta indeterminado por causa de un dilema moral genuino, y si se acepta la unidad del razonamiento práctico, las consecuencias de este dilema dejan de ser relativas a un único sistema y parecen afectar al discurso práctico in totum.

${ }^{10}$ Rocco, Christopher: Tragedia e Ilustración. El pensamiento político ateniense y los dilemas de la modernidad, Andrés Bello Editor, 2000, p. 48.

${ }^{11}$ Ver Rinesi, Eduardo: Política y Tragedia. Hamlet, entre Hobbes y Maquiavelo, Colihue, Bs. As., 2003, p.70 y ss. 


\section{Conflictos normativos y dilemas morales}

Martínez trabaja con dos grandes categorías que procura distinguir: "conflictos normativos" y "dilemas morales". A este respecto, como él correctamente recuerda, existen dos tesis tradicionales en pugna: o bien ambas categorías son discernibles o bien no lo son, en cuyo caso el uso de las denominaciones "conflicto normativo" y "dilema moral" es indistinto.

En esta pugna, él toma partido por la primera tesis, aun si, como creo, luego sucumbe a la segunda.

Ahora bien, la primera tesis admite que los dilemas morales son una subclase de la clase general de los conflictos normativos, se trata de una subclase con relativa autonomía conceptual.

En esta vena, Martínez empieza con la caracterización de la categoría de "conflicto normativo". Él parte de un nivel pre-analítico, esto es, de una noción "intuitiva y pragmática”, según la cual "existe un conflicto normativo cada vez que el agente no puede satisfacer o cumplir con todas las exigencias impuestas por el sistema normativo para ese caso, como ocurriría con el conocido ejemplo de Alchourrón donde el sistema normativo obliga por una parte a detenerse frente a un semáforo en rojo y otra norma prohíbe detenerse en zona militar donde hay un semáforo que se encuentra en rojo".

A esta noción pragmática Martínez aplica la denominada "reconstrucción racional" a fin de obtener un explicatum más refinado que haya dejado atrás dificultades que él advierte. La noción reformulada de conflicto normativo que Martínez ofrece es aquella que comprende cualquiera de las dos situaciones siguientes: a) toda situación en la que resulten aplicables al menos dos mandatos (obligaciones o prohibiciones), que el agente empíricamente puede cumplir individualmente, pero en la que el cumplimiento de cualquiera de ellos elimina la posibilidad empírica de cumplir con los demás; o b) toda situación en la que resulten aplicables al menos un mandato y un permiso, en la que el agente empíricamente puede cumplir el/los mandato/s y ejercitar el permiso individualmente, 
pero en la que el cumplimiento de algún/os mandato/s elimina la posibilidad empírica de ejercitar el permiso, o el ejercicio del permiso elimina la posibilidad empírica de cumplir con los demás mandatos.

Hay varios elementos interesantes sobre los que meditar respecto de esta reformulación. De todos ellos simplemente quiero dejar sugerido el que tiene que ver con la posibilidad empírica del agente de cumplir con las normas en juego. Precisamente, esta cuestión es relevante no solo para el tratamiento de los conflictos normativos sino muy específicamente de los dilemas morales. Ello así por cuanto suele alegarse que los dilemas morales son una excepción al principio kantiano según el cual el "debe implica el puede en sentido empírico", dado que en situaciones de conflicto normativo en general o dilema moral o jurídico en particular, el agente no puede empíricamente realizar el contenido de ambas normas. Esta es una cuestión peliaguda entre otras cosas porque, como afirma Griffin, "estamos en desacuerdo acerca de cuál es exactamente la clase de 'no puede' que debe derrotar al 'debe"'. La cuestión sobre la que llama la atención Griffin resulta especialmente compleja en casos en que intervienen algunos "raros seres humanos que se sacrifican a sí mismos por otros, de modo que ellos sí pueden" 12 .

Sea como fuere, lo central es ver cómo Martínez separa la noción de conflicto normativo respecto de la noción de dilema moral. Para esto resulta menester anticipar dos tesis que Martínez parece defender: la primera es que los dilemas morales configuran una categoría distinguible de la de conflictos normativos, aunque en cierto nivel él use ambas nociones como indistinguibles; la segunda es, en contra del bando de autores que

${ }^{12}$ Griffin, James: “Incommensurability: What's the Problem?”, en Incommensurability, Incomparability and Practical Reason, Edited by Ruth Chang, Harvard University Press, 1997, p.42 y ss. 
niegan la posibilidad misma ${ }^{13}$ de dilemas morales (por caso Donagan), afirmar que éstos son posibles.

Empero, antes de introducirme en la definición de dilema moral suministrada por Martínez y de denunciar lo que creo son sus problemas, quiero detenerme un poco en el tipo de situaciones que a él le interesan en su artículo.

\section{La "remisión a la moral"}

Martínez alega que, para que "una situación de dilema moral resulte jurídicamente relevante, el sistema jurídico debe de algún modo referirse o remitirse al discurso moral para la resolución del caso".

En cuanto a la referencia o remisión que "de algún modo" el derecho hace a la moral, tengo la impresión de que resulta clarificador separar dos hipótesis: una de remisión "explícita” y otra de remisión más bien “implícita”. La primera es ejemplificada por Martínez con una norma expresada por el artículo 1255 del Código Civil Español que remite a la moral en cuanto a fijar límites para el contenido permitido en las cláusulas de los contratos. La segunda es típica de los valores o principios constitucionales que parecen remitir también a la moral cuando emplean expresiones tales como "honor", "libertad", "igualdad", "dignidad”, etc.

Aquí tengo varias cosas para apuntar. En primer lugar, entiendo que, de estas dos clases de remisiones, Martínez está más interesado en

\footnotetext{
${ }^{13}$ Por ejemplo, en su tesis doctoral, "Conflictos constitucionales, ponderación e indeterminación normativa", que de aquí en adelante sólo será referida como "tesis doctoral", Martínez examina posturas como las de Wellman (que tienen correlato con posiciones como las sustentadas por constitucionalistas como De Otto) tendientes a disolver la posibilidad misma de "conflictos normativos" (simples o dilemáticos) con una tesis especificacionista fuerte según la cual tener un "derecho" - o una obligación- supone la especificación de "todas" las condiciones relevantes de aplicación; especificación que supone la tarea de eliminar aparentes conflictos. La analogía de esta postura con la tesis kantiana de deberes morales perfectos y completos resulta palmaria.
} 
la que se vincula con un material constitucional en tanto él constata allí un vínculo más “estrecho" con la moral y, por ende, con la hipótesis de dilemas morales suscitado en un discurso moral. Pienso que la idea de que aquí hay un vínculo "más estrecho" no pasa de ser un mero estereotipo heredado por una corriente que actualmente se conoce como "neo-constitucionalismo", a la que Martínez hace referencia en su trabajo. Hacen falta más pruebas para mostrar porqué este vínculo es más estrecho del que se puede apreciar en un código civil, una ley laboral o un ordenamiento de derecho ambiental. La observación es relevante en cuanto una apreciación tan confiada en este vínculo estrecho explica el hecho de que se deje afuera la posibilidad de dilemas producidos por la colisión entre normas constitucionales y leyes ordinarias o entre normas de leyes ordinarias. En segundo lugar, la idea misma de remisión al "discurso o razonamiento moral" me parece un tanto ingenua, a menos que se precise de qué clase de moral se habla. Aunque la distinción entre "moral positiva" y moral "ideal" tiene un rédito filosófico muy limitado, no estaría mal que Martínez esclareciera este punto de su trabajo. La indicación es importante porque no es una mera cuestión de palabras distinguir entre dilemas "morales" y dilemas "jurídicos". Creo, como ya sostuve, que lo que se suele plantear como un caso testigo de choque entre el derecho y la moral (que para que las cosas sean realmente inteligibles debería ser una moral ideal) no es más que un malentendido montado en una incapacidad de hacer esta distinción. Porque, ¿qué ganancia se obtiene de decir, por ejemplo, que un conflicto entre el derecho a la vida y la libertad de disponer del propio cuerpo expresa la colisión entre dos valores morales? Me atrevo a sugerir que Martínez debería ser más preciso aquí y, para esto, debería explicitar tesis adicionales sobre: i) tipo de moral en juego; ii) alguna tesis sobre la falta de "autonomía semántica" de un material como el constitucional; iii) una explicación de la naturaleza de la clase de autonomía 
que tendría el derecho ${ }^{14}$; y iv) una justificación de porqué los valores constitucionales serían, por su naturaleza moral, tremendamente vagos y con carga emotiva, como él afirma.

Las premisas ii) y iii) son relevantes porque, entre otras cosas, está en juego la explicación de la disputa entre partidarios del derecho natural y del positivismo jurídico e incluso la cuestión de hasta qué punto los segundos, por ejemplo Joseph Raz, son consistentes con su propuesta

${ }^{14}$ En el marco de esta discusión, Andrei Marmor, en su libro Interpretación y Teoría del Derecho, Traducción de Marcelo Mendoza Hurtado, Gedisa, Barcelona, 2001, p.134, específicamente en el capítulo V "Semántica, Realismo y Derecho Natural”, formula una pregunta tan sugestiva como atrayente: ¿Por qué es posible concebir que ciertos dominios normativos, como la moral, tienen aspectos críticos inmanentes o autónomos, mientras que otros, tales como el derecho, sólo pueden ser valorados críticamente desde la perspectiva de otros dominios críticos? Según Marmor, en la actualidad se pueden identificar dos propuestas tendientes a tomarse la pregunta en serio, buscando una vía para pensar la autonomía del derecho respecto de la moral crítica. Esta vía es la noción de "derecho crítico", discernible de la noción de moral crítica. Dos autores, particularmente, parecieran recorrer esta vía: Michael Moore y E.J. Weinrib. El análisis de Marmor, en este sentido, intenta mostrar -y creo que muy convincentemente- que las propuestas de ambos autores no postulan una noción de un "derecho crítico" sino que encubren la aplicación de determinada moral crítica al derecho. En el caso de Moore por la vía de una concepción objetivista de la moral (habría hechos normativos que contarían como criterios de verdad de las proposiciones normativas) o, como en el caso de Weinrib, una concepción racionalista de la moral que erige a la "coherencia" del razonamiento de los jueces en un criterio político moral necesariamente inmanente al derecho. Dado que aquí no es posible hacer una exégesis detallada de las posiciones de los filósofos criticados por Marmor quisiera, más bien, llamar aquí la atención sobre la eventual relevancia de la noción de "derecho crítico". Me parece que puede resultar un trabajo interesante para mostrar otras posibilidades de análisis en supuestos de casos "difíciles" en distintas áreas del derecho (constitucional, penal, civil, etc.) en que las intuiciones acerca de un derecho crítico operen como alternativa a una moral crítica. Si esta alternativa fuese viable, el problema en un caso difícil estaría centrado en una divergencia entre el derecho positivo y el derecho crítico y no entre el primero y una moral crítica determinada. Considero que se trata de una noción que intuitivamente puede abrir líneas de exploración promisorias en cuanto al análisis de las discusiones sobre la relación entre derecho y moral en general; por tanto, acerca del tipo de "autonomía" que en general tendría el derecho respecto de ésta. 
de un positivismo excluyente, en la medida en que admitan que, frente a supuestos de indeterminación del discurso jurídico, hay un recurso a la moral. En este sentido, por ejemplo Bayón, ha visto una suerte de "auto-colapso" de la práctica jurídica ${ }^{15}$, cuestión que aquí no voy a examinar.

La premisa iv), por su parte, requiere de mayor fundamentación. Primero, porque considerar vagos a los valores constitucionales, lo cual explicaría la tesis de remisión a un discurso moral que también está indeterminado, deja de lado otra posible consideración: una como la sustentada por Ronald Dworkin cuando sostiene que los valores en cuestión no son 'vagos' sino 'abstractos' ${ }^{16}$. No está de más recordar que, aun si la tesis de Dworkin no es plenamente diáfana, permite dar cuenta de una distinción relevante como la de "conceptos" y "concepciones" ${ }^{17} \mathrm{y}$, por extensión, dar cuenta de la relación entre "legisladores" (que trabajan sobre conceptos) y "jueces" (que desarrollan concepciones). Este último es un aspecto que está en el centro del interés de Martínez puesto que los casos que él estudia tienen que ver con jueces que, enfrentados a controversias jurídicas, se involucran con un discurso moral que suscita una situación de dilema. Y, ya que de Dworkin se trata, tampoco está demás recordar que él sostiene la tesis de que situaciones como la de los dilemas morales deben ser raras si los jueces disponen de una adecuada concepción de los valores o principios constitucionales o morales en la que éstos no choquen. ${ }^{18}$

\footnotetext{
${ }^{15}$ Ver Bayón, Juan Carlos: "Derecho, convencionalismo y controversia", en La relevancia del derecho. Ensayos de filosofía jurídica, moral y política, Pablo Navarro y Cristina Redondo (Compiladores), Gedisa, Barcelona, 2002, p. 68.

${ }^{16}$ De hecho, cuando Dworkin se refiere al término "vaguedad" para referir a los conceptos usa las comillas siempre. Ver Dworkin, Ronald: Los Derechos en Serio, Traducción de Marta Guastavino, Planeta Agostini, Barcelona, 1993, especialmente p. 216.

${ }^{17}$ Dworkin, Ronald: Los Derechos en Serio, op.cit., pp. 213-216.

${ }^{18}$ Véase Dworkin, Ronald: “Do liberal values conflict?", in The Legacy of Isaiah Berlin, Edited by Ronald Dworkin, Mark Lilla and Robert. B. Silvers, New York Review Books, 2001, p. 89. Ver también de la misma obra The Legacy of Isaiah Berlin, en "Discussion", sugerencias de Dworkin sobre esto en p. 126.
} 
Segundo, porque si los valores constitucionales tienen, como atributo prominente, carga emotiva, afirmación que da por sentada la validez inconcusa del no cognitivismo, creo que a la larga la posibilidad de distinguir los simples conflictos constitucionales de los dilemas morales se disuelve puesto que las consecuencias serían las mismas en ambos casos: el juego más o menos velado de un juez subjetivo y fuertemente discrecional. Así, esta consecuencia, que Martínez casi al final de su artículo atribuye al reconocimiento de dilemas morales genuinos, sería también atribuible a los conflictos constitucionales. Y, además, implícitamente generalizaría una tesis -estilo Guastini ${ }^{19}$ - según la cual la naturaleza de la interpretación jurídica y particularmente de la ponderación es puramente subjetiva, en el sentido de que ésta no puede ser controlada racionalmente, sea lo que fuere que esto último signifique.

\section{Las "controversias" sobre los dilemas morales según Martínez}

Martínez detecta la existencia de distintos "conceptos" de dilema moral y encuentra que, del hecho de que los filósofos no hayan advertido esto, se explica la existencia de "falsas controversias" en que, por ejemplo, ambos autores tengan razón.

Sin entrar aquí a discutir sobre la naturaleza de las controversias filosóficas, yo encuentro que Martínez subestima demasiado a los filósofos, especialmente los de la moral, que han discutido sobre los dilemas morales. Así, Martínez sería como el "ojo de Dios” que puede ver que la discusión de estos filósofos no es más que la expresión de malentendidos verbales del tipo reflejado en aquel legendario caso, tratado por William James, donde un grupo de excursionistas discute acaloradamente sobre si una persona que gira en torno a un árbol tratando de ver a una ardilla, está o

\footnotetext{
${ }^{19}$ Ver Guastini, Riccardo: "Los principios en el derecho positivo", Distinguiendo. Estudios de teoría y metateoría del derecho, Traducción de Jordi Ferrer i Beltrán, Gedisa, Barcelona, 1999, p.171.
} 
no dando vueltas alrededor de la ardilla. Como se sabe, con un par de distinciones, James mostró que la disputa era verbal y todo dependía de cómo se entendiese la expresión "dar vueltas alrededor" ${ }^{20}$. James sentenciaba que ambos bandos de la discusión tenían razón y que, salvo algunos recalcitrantes, la mayoría comprendió la irrelevancia de la cuestión.

Pero, ¿es así de irrelevante la discusión de los filósofos? Lo que ellos asumen como sus controversias más importantes, ¿no son más que enredos verbales? Y, si es así, ¿cómo se explica que mentes tan lúcidas, aun enterados de que sus diferencias son de índole verbal, persistan en sus posiciones en un vigoroso desacuerdo? ¿No hay acaso espacio relevante para que los desacuerdos genuinos sean -o sigan siendo- operativos? ${ }^{21}$

A esta altura es preciso decir que, ante el panorama de malentendidos verbales, el camino que toma Martínez es el de la estipulación. Como he sugerido ya, pienso que la propuesta definitoria de Martínez no logra realmente identificar qué hay de peculiar en los dilemas morales, al menos en los genuinamente más interesantes y reluctantes a tratamiento racional, respecto de la clase general de los conflictos normativos. Empero, antes de inmiscuirme con lo que implica esta afirmación, necesito situarme en la raíz de la propuesta de Martínez: la estipulación.

A este respecto yo creo, como Brian Bix, que la estipulación es una suerte de "opción por defecto" que tiene el filósofo ${ }^{22}$; con otras palabras, es una suerte de opción legisladora sobre las palabras que intenta, por esta vía, despejar un problema filosófico.

${ }^{20}$ James, William: Pragmatismo, Edición de Ramón del Castillo, Madrid, Alianza, 2000, p. 79.

${ }^{21}$ Para la discusión de esta cuestión me inspiro en trabajos como los de Rodríguez Blanco, Verónica: “Genuine' Disagreements: a Realist Reinterpretation of Dworkin”, en Oxford Journal of Legal Studies, Vol. 21, N.4, 2001, pp. 649-671 y Faerna, Ángel Manuel: “Algo más que Palabras. Consideraciones sobre significado y desacuerdo”, Versión Manuscrita. 22 Bix, Brian: "Conceptual Questions and Jurisprudence", en Legal Theory, 1, 1995, pp. 465-479. Utilizo la versión castellana de Laura Manrique: "Interrogantes conceptuales y teoría del derecho". 
Estimo que, lejos de ser despejado, el problema sigue intocado. Esto es así porque, como ya se sabe, las definiciones estipulativas son concebidas como "arbitrarias" en el sentido primordial de que no son entrevistas como un modo correcto de clasificar el mundo tal como es. En este sentido, sus criterios de evaluación habituales tienen que ver con la utilidad o conveniencia tanto para la especulación teórica como para el debate sustantivo que sobre un problema determinado se entable. Así, los criterios de las estipulaciones son internos a las mismas.

De esta suerte, sugerir que se puede "elegir" si llamar "dilema moral" a "x" o a "z" me parece una posición cándida desde que, de esta actividad de estipulación, no se sigue consecuencia práctica relevante alguna, pues el "fenómeno subyacente al nombre quedará inalterado independientemente de cómo se lo denomine"23.

\section{La “definición” de dilemas morales ofrecida por Martínez}

Pese a lo anterior, Martínez recurre a la estipulación como método para dar cuenta de los dilemas morales. Los rasgos con que los caracteriza son: i) constituir "conflictos normativos" de una categoría específica, esto es, conflictos normativos "no simples"; ii) estos conflictos se caracterizan más apropiadamente por su "estructura" y no por el grado de "importancia" o por la intensidad de "problemas" que éstos generen; iii) estrictamente por 'dilema moral', Martínez entenderá "toda situación de conflicto normativo (moral) en la que el sistema normativo (moral) carezca de recursos (criterios, escalas, procedimientos, etc.) para poder determinar la obligación definitiva de entre las distintas obligaciones prima facie en conflicto"; esto es, "serán dilemáticas aquellas situaciones de conflicto en las que no pueda

${ }^{23}$ Tomo este razonamiento de Soper, Philip: "La elección de una Teoría Jurídica con Fundamentos Morales”, en Derecho y Moral. Ensayos analíticos, Jerónimo Betegón y Juan Ramón de Páramo Directores y Coordinadores, Ariel, Barcelona, 1990, p. 57. 
establecerse la obligación definitiva"; iv) dos claros candidatos a dilema son, por una parte, la "equivalencia" de las alternativas; por la otra, los casos de "incomparabilidad". De estos rasgos, por lo pronto, quiero ocuparme de iii). Martínez cree que el rasgo de "importancia" no es un candidato plausible para dar cuenta de los dilemas morales debido a que es un criterio demasiado "vago" y "subjetivo". Sin embargo, luego, al caracterizar las nociones de "obligación" y "permiso" moral con apoyo en Zimmerman, él emplea ideas que tienen una fuerte semblanza con este criterio de "importancia” que él descarta. Así, conforme a Zimmerman, "un comportamiento es moralmente obligatorio cuando su realización es superior (tiene más valor deóntico) que su no realización...”, mientras que "algo está moralmente permitido cuando su realización no es peor (no tiene menor valor deóntico) que su no realización...”.

Con todo, el malentendido que pudiera surgir respecto de la consistencia de las ideas de Martínez debería evaporarse. Cuando él propone sustituir el criterio de "importancia" por el de "estructura normativa" me parece que está pensando en que la importancia o el mayor o menor valor deóntico en la realización u omisión de una acción no dependen de apreciaciones subjetivas de un intérprete sino de la naturaleza y relaciones de los elementos de un sistema normativo que se adopte como referencia de acciones. Yo creo, sin embargo, que parte del resquemor de Martínez hacia el criterio de importancia y su tilde de "subjetivo" puede remontarse a una doble fuente: por un lado, a la idea tácita según la cual en la moral no hay "autoridades" que determinen factores de importancia en forma independiente a un intérprete; por otro lado, a que el criterio de "importancia" o de "problema" tiene un tufillo muy parecido al que tendría la teoría del "mal inevitable" o de la "consecuencia desagradable" con la cual se intenta enfocar los dilemas morales. Luego me referiré -y defenderé como más idóneo- este enfoque al que puede llamarse el "enfoque trágico" de los dilemas morales, cuyo alcance intentaré precisar más adelante.

Por ahora, lo que hay que subrayar es que el criterio elegido por Martínez para definir la naturaleza de los dilemas morales es el de 
"estructura normativa”. Este criterio sería el más aceptable para discriminar conflictos normativos "simples" (o simpliciter) de otros -Martínez no usa esta expresión- más “complejos” como los dilemas morales. De este modo, él afirma que "los dilemas morales serán aquellos conflictos normativos (morales) que presenten cierta estructura, que no presentan siempre los conflictos normativos". Mis razones para pensar que Martínez no logra distinguir acabadamente los conflictos normativos simpliciter de los dilemas morales no obedecen, aunque en parte se alimenta, de algunos deslices de sus frases. Así es muy común que en varias partes de su trabajo él use como indistintas ambas categorías y, en el párrafo que acabo de citar, diga que esta estructura que se presenta en los dilemas morales no se presenta "siempre" en los conflictos normativos. El término 'siempre' es el tipo de desliz al que me refiero y que, en forma no consciente, hace que la distinción entre dilemas morales y conflictos normativos colapse pues depende de una estructura meramente contingente, que no siempre separará una categoría respecto de la otra.

Más promisorio para el análisis me parece el rasgo que Martínez atribuye a los dilemas morales en iii), esto es, la ausencia de criterios, escalas o procedimientos para resolver situaciones como las planteadas por los dilemas morales. Este criterio apunta a la idea según la cual los dilemas morales son conflictos "irresolubles racionalmente", sea lo que fuere que esta expresión signifique. Así, la distinción que Martínez traza entre conflictos normativos "simples" y conflictos normativos qua "dilemas morales" (recuérdese que él no examina la idea de dilemas jurídicos cuyo provecho ya insinué antes), parece correlativa con la usual distinción entre conflictos normativos "resolubles" o "aparentes" y conflictos normativos "irresolubles" o "genuinos". Empero, la correlatividad no ayuda a la distinción firme que Martínez procura conseguir. Pues, quedarse con el segundo par de distinciones -conflictos resolubles e irresolubles- hace de inmediato surgir la pregunta por la relevancia de usar la expresión ‘dilema moral'. ¿Qué agrega esta categoría a lo que los juristas ya están habituados a tratar cuando enfrentan decididamente conflictos aparentes 
o cuando se rinden soterradamente en supuestos en que los conflictos se revelan como reluctantes a una solución racional?

Es claro que esta pregunta no puede ser estudiada apropiadamente si no se especifica qué se entiende por 'resolución' o 'no-resolución' "racional", cuestión decididamente importante. A este respecto, Martínez menciona solo al pasar la ausencia de criterios, escalas o procedimientos como indicadores de la existencia de conflictos irresolubles. Desde ya téngase en cuenta que esta aproximación no está exenta de dificultades pues el problema de los dilemas morales -o jurídicos- parece reducirse a la hipótesis de lagunas normativas ${ }^{24}$, esto es, a la 'ausencia' de criterios para resolver conflictos. Pero, así, ¿cuál es la especificidad de los dilemas morales?

Ahora bien, una cuestión que surge es la siguiente: ¿en qué 'criterios' o 'procedimientos' está pensando? La pregunta no es sencilla porque, en el fondo, levanta una cuestión típica de filosofía de la mente: cómo conocer contenidos mentales de otros. Sorteando, sin embargo esta posible dificultad, yo creo que lo que él tiene en mente con términos tales como 'criterio' y 'procedimiento' se vincula con la cuestión del procedimiento de ponderación; más concretamente con la constatación de la imposibilidad de ponderar en un sentido racionalmente controlable, o de establecer un esquema coherente de los valores en pugna sobre el trasfondo de casos paradigmáticos (como propugna Susan Hurley a quien él cita en su tesis doctoral). Por otro lado, parece diáfano que, cuando usa el término 'escalas', está pensando en la posibilidad latente de "ordenar un conflicto" sea sobre una base "cardinal" (como propone el utilitarismo) u "ordinal" (como proponen autores como Robert Alexy). Yo no tengo ningún reparo que hacer prácticamente a todo esto.

\footnotetext{
${ }^{24}$ Hay innumerables definiciones de laguna normativa. Aquí tomo la expresión 'laguna normativa' en un sentido amplio que no tiene porqué coincidir con la definición suministrada por Alchourrón y Bulygin en Normative Systems.
} 
No obstante, mi punto es que, por este camino, no se logra una distinción firme y estable entre conflictos normativos y dilemas morales, ni siquiera por conducto de los rasgos de "equivalencia" e "incomparabilidad" con que Martínez caracteriza a los dilemas morales. Muchos juristas, incluso, podrían pensar que la idea de dilema moral es un plus innecesario en cuanto se admita que hay muchos conflictos constitucionales que se definen por el empate de los principios o valores contendores o de su imposibilidad de comparación. Más aún, si la teoría de la ponderación que se adoptase fuese una del estilo Guastini, donde "ponderar" no es más que una operación subjetiva (a pesar de la ideología de turno que encubra este carácter subjetivo) las consecuencias de estos conflictos son las mismas que usa Martínez para establecer diferencias conceptuales con los dilemas morales.

Pero es que además hay un obstáculo muy fuerte todavía aquí. Recuérdese que en la nota a pié de página $n^{\circ} 12$, Martínez observa que “este vínculo entre el derecho y los dilemas morales puede plantearse también en cualquier situación de indeterminación normativa debida a un problema de laguna normativa o de antinomia. En esas situaciones, como (desde la perspectiva positivista hartiana) el decisor goza de discrecionalidad, puede acudir al razonamiento moral para tomar su decisión, y podría ocurrir que en el ámbito moral se plantease un dilema”. Esta nota avala la idea de que no es clara cuál es la relación entre dilemas morales y derecho, dilemas morales y conflictos normativos y dilemas morales e indeterminación. Ello es así por cuanto las consecuencias "son las mismas": la "discrecionalidad" 25 del juez o de cualquier otra autoridad normativa, cuestión a la que Martínez alude en la última parte de su trabajo.

En suma, los dilemas morales son análogos a fuentes de indeterminación como las "lagunas normativas" y las "antinomias", pero

\footnotetext{
${ }^{25}$ Se supone que "fuerte" en el sentido dworkiniano del Modelo de las Normas I.
} 
¿cuál es el tipo específico de "indeterminación” -si lo hay- suscitado por los dilemas morales? ¿Es la existencia de "inconsistencia” o "antinomia" un indicador exclusivo de dilema moral? La respuesta a esta última cuestión tiene carácter negativo en el trabajo de Martínez. Sin embargo, como se ve, él traza una analogía; analogía que es problemática si uno escoge enfoques como los de Bernard Williams o Isaiah Berlin, conforme los cuales, los dilemas morales no pueden ser tratados en esos términos pues los valores o fines rivales no son verdaderos ni falsos ${ }^{26}$ y no hay elección que los pueda tornar tales y eliminar las ideas de "sacrificio" y "remordimiento", que Martínez no examina en este trabajo objeto de discusión ${ }^{27}$.

Por último, hay que ver el rasgo apuntado por Martínez en iv). Un dilema moral estaría presente allí donde se verifique "equivalencia" de o "incomparabilidad" entre alternativas en juego. Ya dije que estos mismos rasgos pueden estar presentes en conflictos constitucionales, pero la réplica de Martínez a este punto podría ser que, lo que llamo 'conflictos constitucionales simpliciter' no es más que el disfraz de un genuino dilema moral. Pero, aún concedido esto, ¿si ambas categorías son intercambiables en el uso habitual, qué justifica más allá de ese uso la diferencia? Esta pregunta no habré de responderla aquí porque considero que Martínez tiene algo que decir al respecto.

\footnotetext{
${ }^{26}$ La posición de Berlin o Williams podría ser interpretada como una movida "anti-teórica" en filosofía moral. Ver sobre esto Clarke, Stanley and Simpson, Evan Eds.: "Introduction. The Primacy of Moral Practice", en Anti-Theory in Ethics and Moral Conservatism, State University of New York Press, 1989, pp. 1-25. Por cierto que se podría bloquear la idea con el pensamiento según el cual las relaciones lógicas entre normas (por ejemplo la de consistencia o la de inconsistencia) no necesitan compromisos tan fuertes. Por ejemplo, Alchourrón y Martino han bregado por la idea de que es posible concebir una noción de consecuencia lógica neutral a la verdad. (Cfr. Alchourrón, Carlos y Martino, Antonio: “Logic Without Truth”, Ratio Iuris, Vol.3, N.1, 1990, pp. 47; 51-53.).

${ }^{27}$ Aunque sí en su tesis doctoral.
} 
Ahora bien, supóngase que admito que los rasgos ya mencionados son atrayentes candidatos a la hora de tratar con dilemas morales. Con estas miras, conjetúrese que un sujeto $\mathrm{S}$ se encuentra enfrentado a un serio dilema en un supermercado en dos hipótesis: i) sea porque la elección de un queso caro tiene el mismo valor que la elección de un vino caro y no puede comprar ambos; ii) sea porque enfrenta la posibilidad de comprar un tipo de helado que le gusta muchísimo (satisface su placer gastronómico) pero que al mismo tiempo le produce serias molestias gástricas, afectando el valor salud. Supóngase, solo por el experimento mental que empleo, que ambos valores "placer gastronómico" y "salud" no pudiesen ser comparados por $\mathrm{S}$, incluso descontando que $\mathrm{S}$ es un agente que cuenta con toda la información relevante y con fino poder deliberativo.

La pregunta que emerge es ¿dónde hay un dilema moral aquí? Supóngase ${ }^{28}$ que ninguno, aún si hubiese un genuino "dilema". Esto muestra, nuevamente, que alegar los rasgos de 'equivalencia' e 'incomparabilidad' solo pueden ser útiles, con reservas, pues ellos podrían extrapolarse a cualquier tipo de dilema relativo a cualquier tipo de dominio.

Dos observaciones más. Primero, destacar que Martínez reconoce que las "consecuencias" de los dos rasgos mencionados son, finalmente, las mismas: la discreción por parte del que tenga que resolver el problema o la pura elección ${ }^{29}$ si se trata de un mero agente moral. Si es así, su distinción conceptual solo tiene aplicación en el campo de lo teórico, pero su relevancia se desdibuja en el campo práctico donde las

${ }^{28}$ Digo que "supóngase" porque desde cierta interpretación del "florecimiento" de una vida o "eudaimonía”, el dilema podría ser moral. Tal cosa podría ocurrir si se escogiera una versión "comprehensiva" de la eudaimonía. Sobre esta versión véase Nagel, Thomas: “Aristóteles: sobre Eudaimonía”, en Otras Mentes, Traducción Sandra Girón, Gedisa, Barcelona, 1995, p. 145 y ss.

${ }^{29}$ Elección guiada por la idea de que habría una relación de indiferencia en las preferencias por cualquiera de las acciones. Dicho en el vocabulario admitido por Martínez, la idea es que ambas acciones "estarían moralmente permitidas". 
consecuencias parecen idénticas. Siendo así, se trata de una distinción de gabinete que no guarda correlación con la práctica, lo cual hace suponer que la distinción, tal como se plantea en teoría, debería ser o bien abandonada o bien reformulada, a menos que se suscriba el lema de "peor para la práctica...".

Segundo, poner de manifiesto de manera muy especial que, además de los dos rasgos "explícitamente" mencionados por Martínez, (repito: equivalencia e incomparabilidad) se podría agregar a la lista un "tercer" rasgo que, si bien él menciona, está más bien "implícito” en su texto. Para ver este elemento recuérdese que en iii) Martínez argumenta que "serán dilemáticas aquellas situaciones de conflicto en las que no pueda establecerse la obligación definitiva". En el fondo, la idea es que si hay un genuino dilema moral ninguno de los requerimientos en pugna puede "superar" o "derrotar" al otro. Es decir, a las ideas de equivalencia e incomparabilidad, Martínez añade la de "inderrotabilidad" de las pretensiones normativas en juego. ${ }^{30}$ Creo sinceramente que este criterio es más robusto que los anteriores para dar cuenta de las intuiciones que subyacen a la creencia en dilemas morales genuinos. Si se admite esto, la consecuencia es importantísima: queda bloqueado cualquier procedimiento de ponderación. Es más, la idea según la cual la naturaleza de este procedimiento es subjetivo resultaría válida en cuanto se afirme que un ordenamiento de un conflicto que tenga corte subjetivista deja inalterable el fenómeno de la radical inderrotabilidad de las pretensiones en juego.

\section{Una alternativa más plausible: el enfoque "trágico"}

Como ya he sugerido, creo que un enfoque trágico de los dilemas morales sería una alternativa más plausible para dar cuenta de esta "especificidad" que Martínez busca para los mismos. Por cierto, soy

\footnotetext{
${ }^{30}$ En la misma línea, McConnell, Terrance: "Moral Dilemmas", in Stanford Encyclopedia of Philosophy, p. 2. (se encuentra en internet)
} 
consciente de que no se trata de proyectar una luz nueva sobre los dilemas morales sino más bien de ir a la búsqueda de un enfoque ya conocido pero potente al momento de hacer inteligible la especificidad de los dilemas morales respecto de los conflictos normativos simpliciter.

Así, en un pasaje de su trabajo, Martínez admite, respecto de los dilemas morales, que "una posibilidad es pensar que cualquier decisión que se tome estará igualmente injustificada y será por ello incorrecta, de modo que no es posible evitar el "mal" o el "error"" 31 . En otras palabras, cualquiera de los caminos que escoja el agente resulta "intratable" e "intransitable". ${ }^{32}$

Uno de los filósofos del derecho ${ }^{33}$ de habla hispana que introdujo este enfoque, como ya se sabe, fue Manuel Atienza ${ }^{34}$, aunque él no extrajo todas sus consecuencias ${ }^{35}$.

La idea según la cual hay casos "trágicos", desde luego, es bastante compleja porque involucra numerosos problemas, incluso metafísicos (por caso, referidos a la libertad del agente). Dado que en otro trabajo me he ocupado con más detalle de esta complejidad ${ }^{36}$ aquí no avanzaré mucho más que esto.

${ }^{31}$ Por cierto que el "error", desde una teoría ética como la de Aristóteles, podría ser recusado desde que, según el estagirita, el agente que actúa trágicamente estaría dominado por la "hamartia" o la "hubris"; su acción no sería trágica sino "patética". Pero el error que tengo en cuenta aquí es objetivo o puede correlacionarse con un "estado de cosas".

${ }^{32}$ Lesky, A.: Historia de la Literatura Griega, Madrid, Gredos, 1985, p. 285.

${ }^{33}$ En filosofía moral y política este enfoque ha sido suscripto, entre otros, por Sinnot Armstrong, Bernard Williams, Martha Nussbaum, Isaiah Berlin, etc.

${ }^{34}$ Por ejemplo en "Los límites de la interpretación constitucional". De nuevo sobre los casos trágicos, Isonomía, Revista de Teoría y Filosofía del Derecho, № 6, Itam-Fontamara, México, pp.7-30; Tras la Justicia. Una introducción al Derecho y al Razonamiento Jurídico, op.cit, especialmente capítulo V, p. 177.

${ }^{35}$ He intentado mostrar esto en "Conflictos trágicos genuinos, ponderación y límites de la racionalidad jurídica”, en Isonomía, Revista de Teoría y Filosofía del Derecho, México, 2006, n² 24, págs. 93-114.

${ }^{36}$ Ver Lariguet, Guillermo: “Conflictos Trágicos y Derecho. Posibles Desafíos”, en Doxa, Cuadernos de Filosofía del Derecho nº 27 (2004), pp. 317-348. 
Creo que la noción de "caso trágico" 37 puede ser fecunda para poner en evidencia: i) el carácter intratable de un caso en cuanto no es posible avizorar una respuesta racional para el mismo; ii) la existencia de $\operatorname{aspectos}^{38}$ del mundo contingentes ${ }^{39}$, variables, inestables, difícilmente

${ }^{37}$ No tengo problemas en admitir que hay "casos trágicos" que no involucran "dilemas". Por ejemplo, es común encontrar que la gente refiere a una muerte imprevista o accidental como un evento trágico. Ello así por cuanto hay ciertos rasgos (por ejemplo los referidos a lo "imprevisto" y a la "muerte" o "destrucción") que tienen vínculos con la intuición de tragedia, aun si no hay dilema. Pero los dilemas más intensos, o francamente genuinos, creo, son aquellos que tienen ribete trágico, tal como argumentaré. De modo que aun si es verdad que hay tragedia sin dilema moral aquí defenderé que no vale la inversa, al menos para situaciones dilemáticas de un alto grado de intensidad o dramatismo.

${ }^{38}$ Estos aspectos imprevisibles son conocidos en la literatura bajo el nombre de "suerte moral" que los griegos oponían a la idea de "auto-suficiencia", "florecimiento moral" o "eudaimonia". Ver Nussbaum, Martha: The Fragility of Goodness. Luck and ethics in Greek tragedy and philosophy, Cambridge University Press, 1986, p. 3 y ss. Según Nussbaum, Kant tendió durante siglos un "manto de sal” sobre el problema pues intentó "eliminarlo" mediante la creación de un reino moral "incondicionado" por los avatares que ocurren en el mundo empírico. Esto explica toda una maquinaria conceptual destinada a eliminar la posibilidad de dilemas morales genuinos. Ver Nussbaum, Martha: The Fragility of Goodness. Luck and ethics in Greek tragedy and philosophy, op.cit., p.4. Téngase en cuenta, a su vez, que la idea de "suerte moral" tuvo capital importancia en el Renacimiento, apareciendo bajo la forma de la "Diosa Fortuna". El interés de los filósofos en ese momento era si era posible y cómo oponer a la fortuna la virtù, entendida esta última como la capacidad de enfrentar situaciones variables e inestables. En ocasiones, los griegos, inmersos en situaciones trágicas, confiaban en que esta capacidad, como sostiene Áyax, le iba posibilitar "alcanzar la gloria, aún al margen de los dioses". No está de más recordar que, en buena medida, la dicotomía fortuna-virtù fue una preocupación que Maquiavelo trasladó a su obra El Príncipe; traslado enmarcado en el "descubrimiento" de Maquiavelo de la existencia de conflictos inevitables y trágicos de valores inconmensurables. Ver Rinesi, Eduardo: Política y Tragedia, op.cit., pp. 37-65.

${ }^{39} \mathrm{La}$ presencia de estos aspectos da lugar a un tipo de dilema generado por el mundo y no por el propio agente. 
previsibles, a veces inmanejables ${ }^{40}$, y que inciden en la caracterización de propiedades prácticamente idiosincrásicas, válidas para un caso y no necesariamente para otros, de modo tal que resulta problemático pensar en la existencia de reglas o principios universales que regulen estos casos de antemano ${ }^{41}$. Cuando más adelante discuta la propuesta normativa de Martínez, regresaré a este punto; iii) la idea de que cualquier camino escogido por el agente es desastroso y por eso se elimina seriamente la idea de respuesta correcta; iv) la revelación de un genuino aspecto del carácter moral del agente (es un conducto para conocer aspectos de la moralidad profunda del agente); v) la posibilidad de un cambio de "horizonte moral" puesto que, después de tomar una elección o decisión trágica, el agente podría "no ser el mismo"; dicho en forma más precisa, podría haber alterado su "identidad moral". Respecto de este último punto adviértase que el "cambio" al que llevan las elecciones trágicas puede ser bastante "radical". Este cambio, con distintos grados, puede afectar tanto a personas (Edipo por ejemplo) o sistemas normativos. En efecto, el supuesto de cambio radical de identidad presupone la idea de "destrucción" (que no sólo se concibe de manera "física"); así, puede hablarse de destrucción de personas (llegando incluso a la "muerte", tema clásico de la tragedia) o también de sistemas (que pueden ser "sustituidos" por otros ${ }^{42}$ ).

\footnotetext{
${ }^{40} \mathrm{Me}$ refiero a que puede haber aspectos de la personalidad del agente que éste no puede domeñar (o "evitar"). Pienso en casos al estilo Fedra y su amor por Hipólito (hijo de Teseo, su "marido oficial”). En hipótesis de este tipo, tratadas en la literatura por Eurípides o Racine, hay sin duda muchas cuestiones enmarañadas que no puedo tratar en este trabajo. ${ }^{41}$ Es claro que estoy sugiriendo un vínculo entre los dilemas morales y el particularismo moral. Pero sobre este vínculo y el tipo de particularismo en juego no puedo discutir aquí. ${ }^{42}$ La idea de "destrucción" aparece también en la idea de cambio radical de sistemas normativos en el vocabulario de los juristas. Cuando los juristas advierten que un sistema, por ejemplo, está a punto de destruirse, suelen activar la idea (también ínsita en la discusión de los dilemas morales) de "sacrificio". Por ejemplo, si un sistema constitucional basado en derechos individuales está en serio peligro, muchos justifican un "sacrificio" de esos derechos o algunos derechos con la presunta finalidad de "salvar" el sistema para el futuro. Desde
} 
Vale la pena aclarar, respecto de los rasgos i) a v) arriba mencionados, que no necesariamente deben presentarse todos para calificar como "trágico" a un caso. Como sugerí al comienzo de este trabajo, es posible que la expresión universal "dilemas morales" sea una simple 'etiqueta' para dar cuenta de situaciones conflictivas de diversos grados o intensidades de complicación. Por ejemplo, un rasgo como v) no necesariamente tiene que darse para que estemos habilitados a decir que la situación " $\mathrm{x}$ " constituye un dilema moral genuino, aún si esta situación es menos dramática que otras situaciones dilemáticas en que v) se presente. Pero, incluso dándose v), es factible que el cambio de "horizonte moral" se pueda presentar a través de una paleta de diversos grados de intensidad. Lo que estoy insinuando aquí probablemente deba verse como un conjunto de afirmaciones en el marco de un "work in progress". Con todo, pienso que una tarea que se espera que la filosofía cumpla es la de ser capaz de distinguir diversas situaciones dilemáticas, identificando los "rasgos" que las caracterizan. Pero estos rasgos no necesariamente deben ser vistos como el ofrecimiento de un repertorio de condiciones necesarias y suficientes de definición de "dilemas morales". No estoy diciendo que este "enfoque" de los rasgos característicos de los dilemas morales deba quedar descartado pues creo honestamente que la cuestión metodológica de cómo enfocar el análisis

luego, que estas ideas pueden volverse peligrosas según el uso que se haga de ellas. Por ejemplo, Carl Schmitt empleaba la idea de "estado de excepción” como una vía que habilitaba a la "suspensión total de la vigencia de un orden jurídico" y una de las finalidades, al menos de la "dictadura comisarial", era salvarlo o preservarlo; si esto no era posible, operaba lo que Schmitt llamaba la dictadura "soberana" que instauraba un nuevo orden. Sobre esto puede verse Agamben, Giorgio: Estado de Excepción, Adriana Hidalgo Editora, 2005; Campderrich, Ramón: La palabra de Behemoth. Derecho, política y orden internacional en la obra de Carl Schmitt, Trotta, Barcelona, 2005. El "estado de excepción” funciona de manera muy parecida al "ius necessitatis" que le interesaba a Kant, Immanuel: $L a$ Metafísica de las Costumbres (1797), Estudio Preliminar de Adela Cortina Orts, Traducción y notas de Adela Cortina Orts y Jesús Conill Sancho, Altaya, Barcelona, 1989, p. 45. 
conceptual de los dilemas morales es relevante. Así, una cuestión raigal es debatir acerca de cuál es la mejor explicación filosófica ${ }^{43}$ de una categoría como la de dilemas morales. Sea como fuere, lo que sí creo es que no estamos obligados a construir un lecho de Procusto para encajar, a como de lugar, situaciones dilemáticas. En esta línea, los rasgos ${ }^{44}$ que he mencionado son más bien guías útiles a la hora de identificar genuinas situaciones dilemáticas y no categorías que el filósofo pueda usar con desdén, permitiéndole sostener, frente a situaciones que no presenten "todos" los rasgos mencionados, el apotegma de "peor para el mundo".

Ahora bien, dejando a un lado mi aclaración precedente, resultaría sensato esperar que Martínez intentara destruir todo mi argumento sobre el carácter auspicioso del enfoque trágico. De hecho, en su tesis doctoral, él construye una réplica a un argumento del estilo del que presento, en los siguientes pasos: i) "el argumento se comporta de modo distinto según este 'mal inevitable' se entienda en sentido moral o en un sentido valorativo extramoral, pero en ninguno de esos dos casos resulta muy afortunado: la conclusión será que se trata de un argumento o bien irrelevante o bien falso, con lo cual no nos es de ninguna utilidad". El 'mal' en cuestión, si es "moral", "se identifica con el incumplimiento de una obligación moral: se provoca un mal cuando no se satisface lo que es moralmente obligatorio" "45; ii) en cualquiera de los dos casos, no obstante, se produce un mal moral, por lo que éste se encuentra conceptualmente

${ }^{43}$ Debate que, por ejemplo, se encuentra reflejado en el penetrante análisis ofrecido por Joseph Raz en "Two Views of the Nature of the Theory of Law. A Partial Comparison", en Hart's Postcript. Essays on the Postcript to The Concept of Law, Edited by Jules Coleman, Oxford University Press, New York, 2001, pp.1-37.

${ }^{44}$ En consecuencia tampoco creo que los rasgos que menciono agoten necesariamente lo que he denominado el enfoque trágico. Sí creo que son rasgos paradigmáticos que exigen una investigación detallada.

${ }^{45}$ Para Martínez, “el mal puede ser 'definitivo', si lo que se incumple es una obligación definitiva, o puede ser un mal prima facie, si lo que se incumple es una obligación de ese tipo". 
unido a toda situación de conflicto, sea o no dilemática; iii) por esa razón el argumento es irrelevante: por definición, en todo conflicto se produce al menos un mal prima facie; iv) este no es un criterio que nos permita distinguir los meros conflictos de los auténticos dilemas, puesto que en todos estos casos se produce algún mal moral; v) si éste es el sentido en el que se entiende este mal inevitable, la respuesta evidente es que se trata de una situación meramente contingente; vi) no existe vinculación conceptual alguna entre las situaciones de conflicto o dilema y la presencia de un 'mal' de esta entidad: se podría (admitiendo hipotéticamente la posibilidad de los dilemas) producir una situación dilemática entre dos promesas intranscendentes, en el supuesto de que el sistema moral no pudiera determinar cuál de ellas debería cumplirse. En este caso existiría un dilema y sin embargo el 'mal' que se produciría, teniendo en cuenta la trivial entidad de las promesas, sería mínimo. E incluso en ciertas circunstancias podría ser admisible que nos encontráramos en una situación dilemática cuando las alternativas en conflicto tuvieran ambas consecuencias positivas (o al menos no negativas) desde ese punto de vista valorativo no moral. Si se admite que existe una obligación moral de beneficencia, alguien podría encontrarse en la situación de no saber a qué ONG hacer una donación, pero fuera cual fuera su acción final no existirían consecuencias negativas algunas (a lo sumo un determinado colectivo se quedaría en la misma situación que antes). En suma, pues, es falso que las situaciones dilemáticas supongan la provocación de un 'mal inevitable' en este sentido, puesto que el que se produzca o no dependerá contingentemente de las circunstancias presentes.

La posible réplica de Martínez podría ser percibida como muy persuasiva; sin embargo, no afecta mi argumento sobre la fertilidad del enfoque trágico de los dilemas morales como criterio distintivo de los simples conflictos normativos. Daré algunas respuestas a sus argumentos, observando que:

Argumento i) La distinción entre un sentido "moral" y uno "extra-moral" no afecta el núcleo conceptual de la idea de caso trágico 
sino que, más bien, introduce una distinción entre dilemas "morales" y dilemas "no morales", aun si estos últimos suponen valores en juego (como en mi ejemplo del dilema en el supermercado).

Argumentos ii, iii y iv) Además de esto, hay que decir que la idea de "mal inevitable" puede que esté presente en "todo" conflicto como Martínez afirma pero, no obstante esto, sigue siendo útil la idea de caso trágico para enfocar dilemas morales puesto que la eventual presencia de este mal tiene una incidencia distinta según se trate de un mero conflicto normativo o según se trate de un dilema moral. Yo creo que en un conflicto normativo se puede hacer la distinción entre "mal menor" y "mal mayor", justificándose, mediante algún "procedimiento racional”, la elección por el "menor", evitándose el "mayor". Desde este punto de vista, en un conflicto normativo se puede atisbar un tipo de "respuesta" distinta a la que cabe esperar en un dilema moral enfocado en términos de lo trágico. La respuesta que opte por el mal menor no es una respuesta "tan mala" o "desastrosa". En cambio, en un dilema moral, al menos en uno genuino y muy intenso o dramático ${ }^{46}$, cualquier respuesta es "muy mala" o "desastrosa". Esto es así por cuanto en un dilema moral genuino, si existe, no hay "males menores", o males mayores y menores; cualquier alternativa resulta penosa; cualquier curso de acción es incorrecto. No hay un mal menor en la elección de la madre chechena que tiene que escoger qué hijo (de los dos que tiene) salva de la escuela tomada por un grupo rebelde. Pero incluso, si el balance entre males (que son mayores y menores) fuese posible, tal balance resultaría trivial desde el punto de vista moral.

Argumentos v) y vi) Por lo anterior no me convence la idea según la cual no hay más que un vínculo "contingente" entre el enfoque trágico y los dilemas morales genuinos. Los ejemplos que suministra Martínez, básicamente, son dos: a) el de las dos promesas “intrascendentes”, y b) el

\footnotetext{
${ }^{46}$ Atiéndase a la importancia de este "al menos" pues enseguida introduciré la distinción entre dilemas morales trágicos y no trágicos.
} 
de la decisión que siempre tiene consecuencias positivas. Estos ejemplos me parecen inidóneos para probar su argumento de la vinculación contingente. En lo que incumbe al ejemplo a) hay que decir dos cosas. Primero, que las promesas conceptualmente siempre suponen la alternativa de la "superabilidad" de una obligación contraída ${ }^{47}$, de modo tal que son malos candidatos para pensar el tema de los dilemas morales que tiene que ver con la existencia de mandatos que no pueden superarse mutuamente o ser superados por un valor externo a la contienda entablada entre ellos. Segundo, que aún si se descartara lo anterior, el hecho de asumir que los contenidos de las promesas son "intrascendentes" es un argumento que se auto-frustra puesto que en los dilemas morales genuinos nunca las consecuencias son intrascendentes o triviales. Los dilemas morales realmente importantes no tienen consecuencias así; es posible imaginarlas, desde luego, pero la cuestión de los dilemas morales no forma parte de un mazo de naipes que desempolvamos en un día muy gris para procurar divertirnos un poco. Por supuesto, esto puede ser contestado con un ejemplo como el puesto en b), donde se presenta la situación de "no saber" a qué ONG donar dinero, siendo en cualquier caso positivo el curso de acción que se adopte. Es posible que haya "dilemas" con consecuencias positivas pero esto no afecta la cuestión conceptual de los genuinos dilemas morales que nunca, salvo en una hipótesis rebuscada, implican consecuencias positivas. En los dilemas de Agamenón, Antígona, Orestes, Hamlet, la madre chechena, etc., no hay consecuencia positiva alguna. Pero, incluso, si hubiese hipótesis no extravagantes de dilemas

\footnotetext{
${ }^{47}$ Salvo la hipótesis del "empate" entre dos promesas (ya diré algo de esto) el caso de una promesa de la conducta $\mathrm{x}$ por parte de un sujeto $\mathrm{S}$ a otro sujeto $\mathrm{R}$ presupone una serie de condiciones implícitas que explicitadas podrían jugar como factor de superación de la obligación inicialmente contraída por S con respecto a R. Por ejemplo, si S promete tomar un café con $\mathrm{R}$ y surge una circunstancia imprevista, por ejemplo que su hijo enferma, que le impide cumplir con esta obligación.
} 
morales con consecuencias positivas, ¿qué habría de apremiante o interesante aquí? El agente moral solo tendría que aplicar una relación de indiferencia y elegir cualquiera de las ONG en juego. ¿Qué más se puede añadir a esto? Posiblemente algo que propongo como materia reflexiva a Martínez, a saber: que la idea de consecuencia positiva de su contra-ejemplo puede ser un tanto engañosa si se admite que aun si la ONG que no recibe el dinero en donación no "estará peor" que antes, sí resultará menos favorecida que la ONG seleccionada y quizás -si la comparación entre las ONGs fuese viable- uno no podría decir tan secamente que hay consecuencias positivas en el estricto sentido de la palabra.

Aún si lo anterior se admite queda reluciendo el argumento de Martínez según el cual lo "trágico" tiene un vínculo meramente 'contingente' con la categoría de dilemas morales. Cuando digo que esta idea no me convence, tal como señalé más arriba, debería aclarar que no estoy negando en realidad que el vínculo tenga carácter contingente ${ }^{48}$. Mi falta de convencimiento no supone que yo esté afirmando la existencia de un vínculo necesario. Hay algo de los contraejemplos de Martínez muy sugestivo en este sentido. Brevemente, diría que su ejemplo a) de las promesas, mejorado un tanto, podría mostrar la existencia de un caso donde un sujeto $\mathrm{S}$ promete a dos amigos, que viven en lugares distantes entre sí, visitarlos a la misma hora. Suponiendo que ambas promesas tengan para $\mathrm{S}$ el mismo peso uno estaría aquí frente al rasgo de simetría o empate sobre el que Martínez llamara la atención en su trabajo. ¿Está el sujeto $\mathrm{S}$ expuesto a un genuino dilema moral? Admítase ${ }^{49}$, para ser leal a

\footnotetext{
${ }^{48}$ Le debo a algunas observaciones de Rodrigo Sánchez Brígido la necesidad de aclarar este punto.

${ }^{49} \mathrm{Mi}$ admisión es parte de un experimento mental. Habría que pensar distintas hipótesis de promesas a otros (dejo a un lado la complicada cuestión de promesas a "uno mismo") para determinar si lo que está en juego tiene que ver con valores morales y cuán importantes son los contenidos de las conductas involucradas. Para decirlo en forma breve y sencilla: no es lo mismo prometer a alguien tomar un té que prometerle casamiento, devolver dinero en préstamo o cuidarle en caso de que se encuentre convaleciente.
} 
lo que quiero explicar, que sí. Hay un dilema moral y, no obstante ello, no hay ribetes trágicos a la vista aquí. Concedo este punto pero ello no supone una derrota para la tesis que yo quiero defender, a saber: que la mayoría de las situaciones morales genuinamente dilemáticas, aquellas que evidencian imposibilidad de resolución racional y cuyas consecuencias son negativas y nada intrascendentes, tienen ribete trágico. Quizás haya dilemas morales no trágicos y, en tal caso, esté bien dar cuenta de ellos. Pero me inclino a favorecer la idea según la cual, salvo contados ejemplos, las genuinas situaciones dilemáticas en el terreno moral, al menos las más interesantes y recalcitrantes, tienen carácter trágico en distintos grados de intensidad, tal como señalé antes. Se podría decir, entonces, que mi desacuerdo con Martínez en este punto es más bien parcial, pero no por ello insustancial y esto por dos razones: primero, porque creo que resulta promisorio en la tarea de clarificación del concepto de dilema moral distinguir entre dilemas morales trágicos y no trágicos; segundo, porque entiendo que la mayoría de las situaciones realmente apremiantes en el dominio de la moral, más interesantes y desafiantes, son las que tienen que ver con lo trágico y es de esto de lo que Martínez debiera percatarse.

\section{La propuesta normativa de Martínez}

Como anticipé en la introducción, estimo que la parte sustantiva del trabajo de Martínez, esto es, la construida a partir de su "propuesta normativa", es la parte filosóficamente más atractiva y sugerente de su trabajo.

Sin embargo, los mejores frutos de su propuesta no pueden extraerse simplemente de la parte explícita de su argumento sino que se encuentran implícitos. Como ya he dicho, su parte explícita está en contradicción con algunos de los segmentos más relevantes de su trabajo y su propuesta basada en el valor seguridad jurídica me parece tanto inadecuada como inviable. Es por esto que, para tornar más interesante y consistente su propuesta, tomaré ciertos elementos implícitos de la misma 
$\mathrm{y}$, con el añadido de otros, propondré otra alternativa normativa. Pero antes de ello es conveniente ver lo siguiente.

\section{El problema}

Estoy de acuerdo con Martínez en cuanto a que el corolario de asumir la posibilidad de dilemas morales genuinos implica negar la existencia de respuesta correcta, tanto en el dominio de la moral como del derecho. De todas maneras, como intentaré mostrar enseguida, creo que él termina por desmoronar esta conclusión con su propuesta normativa.

Esto marca un evidente límite para la racionalidad y lleva directamente a las ideas de "elección” y "discreción”, esta última en un sentido fuerte.

En lo que atañe a la idea de "elección”, el argumento es que, ante dilemas morales genuinos -insisto que también frente a dilemas jurídicos genuinos- solo queda el espacio para una elección "arbitraria”.

Que la elección sea "arbitraria" significa, si se ve la cuestión bajo el prisma de la Crítica del Juicio de Kant, que la elección no puede satisfacer criterios de validez intersubjetiva. ${ }^{50}$

${ }^{50}$ Recuérdese que, a diferencia de los juicios teóricos que tienen validez objetiva, Kant atribuye a los juicios prácticos -concretamente los de índole "estética"- validez universal subjetiva. Así, diría Kant, la gente no dice "esto me parece bello" sino "esto es bello", donde el predicado "es" tiene una validez entendida en términos de universalización del juicio. Una cuestión independiente es preguntarse por qué la mayoría de los kantianos contemporáneos acudieron a la Crítica del Juicio y no a la Crítica de la Razón Práctica. Una opinión corriente, al respecto, es que esta última obra sigue ofreciendo una visión muy formalista de la ética. Para mayores comentarios sobre esto véase Castoriadis, Cornelius: "La polis griega y la creación de la democracia", en Los Dominios del Hombre. Las encrucijadas del laberinto, Traducción de Alberto Bixio, Gedisa, Barcelona, 2005, especialmente pp. 103-107. 
Así por ejemplo, en situaciones de equivalencia o empate entre principios, la idea es que se activa una relación de indiferencia, de elección pura $^{51}$. En la literatura filosófica hay gran cantidad de ejemplos de situaciones de esta clase. Por ejemplo, cuando Marx advierte que en la disputa por las horas de descanso y reducción de las horas laborales se tiene, de un lado, al capitalista que procura extenderlas teniendo en cuenta su interés como consumidor y, del otro, al trabajador que procura reducirlas teniendo en cuenta su rol de vendedor, sostiene que se da una antinomia, "derecho contra derecho, cada uno exhibiendo por igual el sello de la ley de intercambios". La conclusión de Marx es cercana a la idea de elección arbitraria cuando concluye que "entre derechos iguales, decide la fuerza" ${ }^{52}$

Lo que acabo de ejemplificar con el pasaje de Marx, supondría que quien tenga que decidir, entre una alternativa $\mathrm{A}$ y una alternativa $\mathrm{B}$, en hipótesis de dilemas morales genuinos, no puede más que ejercer la soberanía de la elección por cualquiera de éstas. Ello así, por cuanto no se puede establecer una relación ordenada de preferencias y solo cabe aplicar una relación de indiferencia o suponer que cualquier conducta se encuentra moral -o jurídicamente- permitida, como ya ha argüido Martínez haciendo pié en Zimmerman. Ahora bien, ¿cuál podría ser el problema de todo esto?

El problema, detectado con agudeza por Martínez, es que tanto el sujeto que defiende la alternativa A como la B podría enfrentar, por

\footnotetext{
${ }^{51}$ Como se sabe, Dworkin tiene diversos argumentos para cuestionar esta idea; uno muy conocido sostiene la tesis de que los "empates son situaciones raras" en sistemas jurídicos "evolucionados" donde existe una suerte de "regla tácita" que prohíbe los empates. He analizado esto con cierto detalle en "Conflictos trágicos genuinos y respuesta correcta. En torno a algunas ideas de Ronald Dworkin”, de próxima aparición en la Revista de la Facultad de Derecho de la Universidad Nacional Autónoma de México.

${ }^{52}$ Citado por Walzer, Michael: Las esferas de la justicia. Una defensa del pluralismo y la igualdad, Traducción de Heriberto Rubio, Fondo de Cultura Económica, México, 1997, p. 198.
} 
ejemplo a un juez, con la siguiente cuestión: que "si realmente da lo mismo, ¿por qué no ampara mi pretensión?” Con otras palabras, "si ni A ni B tienen recíprocamente mayores razones para respaldar su posición, ¿en qué se fundamenta que se sacrifique un derecho para proteger el de la otra parte, cuya pretensión no tiene más fuerza que la otra?"

\section{El recurso al azar}

Una manera de conjurar el desafío de la pregunta planteada en el apartado precedente ha sido, como bien señala Martínez, la postulación del azar, esto es, el recurso a algún mecanismo aleatorio (por ejemplo "tirar la moneda") como una manera de establecer qué parte ganará la querella.

Como es muy conocido, la postulación de mecanismos aleatorios para la toma de decisiones en situaciones de dilema ha sido vista como la postulación de un digno adversario para la llamada "teoría de los grandes números". Según esta teoría resulta moralmente aceptable mantener, por ejemplo, que está justificado salvar al "mayor número", aún si son sacrificados los que se encuentran en el ámbito del "menor número". El recurso al azar sería una manera de evitar la defensa de la tesis según la cual "los números cuentan"; tesis recusada por Taurek, autor citado por Martínez.

El empleo de mecanismos aleatorios, a este respecto, constituiría una forma de garantizar que "todos los afectados cuenten con exactamente las mismas probabilidades". Esto último no es más ni menos que un equivalente de la idea según la cual "las personas son merecedoras de igual respeto, dignidad y derechos".

Precisamente, son estos argumentos de Taurek los que inspiran la propuesta normativa formulada por David Martínez.

\section{La seguridad jurídica}

$\mathrm{Su}$ propuesta normativa se contextualiza en el marco de ciertas características propias del derecho, específicamente las que tienen que 
ver con su conocida dimensión institucional; dimensión que, en la propuesta de Martínez, opera como filtro de la decisión que, en lo atinente al dilema moral, se adopte en sede moral.

Desde una peculiar interpretación de esta dimensión institucional del derecho, Martínez cree que ella no es compatible con el ejercicio de discrecionalidad en "cada caso" que se presente de dilema. Cuando digo que su interpretación es "peculiar" estoy pensando en que: i) es una interpretación que se encuentra distante de la interpretación estándar que de la dimensión institucional del derecho suministra el positivismo jurídico, al menos el hartiano. Téngase en cuenta que, para este positivismo, la dimensión institucional no erradica la posibilidad de indeterminaciones y no excluye, más bien todo lo contrario, la idea de discreción, aun si ésta no debería resultar equivalente con la "arbitrariedad"; ii) creo que, un tanto indiscriminadamente, Martínez emplea la idea de discreción para referirse al derecho y al dominio moral. Esto último me parece un tanto oscuro, si uno admite que la idea de discreción, como ha mostrado Ronald Dworkin, tiene sentido en contextos donde se ejerce una autoridad reglada, por caso, el derecho. ${ }^{53}$

En cualquier caso, resulta esclarecedor destacar que Martínez comprime su interpretación de la dimensión institucional del derecho en un valor: la "seguridad jurídica", entendida en el sentido de poder predecir (normativamente ${ }^{54}$, no psicológicamente) decisiones jurídicas.

Aunque él admite que el valor consistente en "promover la justicia" es relevante, en el contexto jurídico hay que priorizar otro valor. Concretamente, la propuesta de Martínez, y que él considera razonable, estriba en "dar prioridad a la seguridad jurídica frente a la justificación moral en los casos de dilema".

\footnotetext{
53 Ver Dworkin, Ronald: "El Modelo de las Normas I", en Los Derechos en Serio, Traducción de Marta Guastavino, Planeta Agostini, Barcelona, 1993, pp. 83-84.

${ }^{54}$ Sobre esto ver mi "Predicción, Conocimiento y Cambio de Sistemas Jurídicos. Una revisión de la propuesta de Alf Ross", Anuario de Filosofía Jurídica y Social, Chile, 2003, pp. 167-178.
} 
Al respecto, su idea es que esta propuesta está a tono con concepciones de la ponderación de inclinación universalista, como la que propugnarían autores como Alexy, Moreso o Mendonca. Correctamente, él aclara que esta concepción supone que el "cometido de la ponderación no es otro que la elaboración de reglas que, tomando determinadas propiedades, permitan ofrecer una respuesta clara y determinada a las situaciones de conflicto constitucional y, sobre todo, que actúen como reglas, esto es, que permitan la operación de subsunción”.

Ahora bien, Martínez reconoce que esta misma solución no puede extrapolarse automáticamente a situaciones dilemáticas en las que "no puede afirmarse que exista una solución preferible a la otra".

Así y todo, la única manera de garantizar el peso de la dimensión institucional del derecho, tal como ésta es comprendida por Martínez, consiste en, y aquí viene su propuesta concreta, "estipular una regla que ofrezca una solución clara para todas las situaciones de este tipo, aun a sabiendas que tal regla no es mejor que otra que decidiera en sentido contrario". Esto implica que es mejor esto que "dejar la situación indeterminada a expensas de la libre voluntad del decisor o del azar".

Ante todo, adviértase que no queda del todo claro en manos de quiénes quedaría la estipulación de esta regla en la que Martínez cifra sus esperanzas: ¿legisladores o jueces?

Con independencia del interrogante anterior, sinceramente creo que la propuesta de Martínez fracasa por sus propios términos. Mis razones para este aserto son las siguientes: i) dudosamente Martínez da por sentado que, en materia de dilemas morales, el discurso moral supone una justificación moral de la decisión, cosa que a todas luces se da de cabezas con la idea de que en tales situaciones no hay respuesta correcta posible y solo queda la elección arbitraria o el azar; ii) pretender estabilizar decisiones sobre "dilemas morales", decisiones que se dan "caso por caso", me parece un disparate. Como indiqué al presentar los rasgos del enfoque trágico, esto es así por el hecho de que los dilemas morales suelen ser recalcitrantes, entre otras cosas, por sus propiedades 
idiosincrásicas, difícilmente maleables en términos de juicios de universalidad. En otras palabras, si la formulación de reglas supone que las condiciones que puedan operar como virtuales excepciones puedan ser conocidas y listadas, ¿cómo es posible encarar una tarea así con respecto a situaciones dilemáticas que, por lo general, se caracterizan en términos de casos intrincadamente complejos sujetos a propiedades no susceptibles de conocimiento a priori?; iii) resulta impreciso a qué ámbito Martínez está refiriendo la demanda de seguridad jurídica en el sentido de formular una regla que "estipule" para "todos" los casos una manera de resolver en sentido determinado. En primer lugar pienso que hay que meditar sobre la función latente de esta regla estipulada, a la que refiere Martínez. Esta función, a mi juicio, no es otra que la de operar como una suerte de "regla de clausura" que prescriba que, "frente a conflictos dilemáticos establecidos entre A y B", "siempre deberá ganar A" o "siempre deberá ganar B". Pero hay que ser conscientes de que esta regla -parecida en funcionamiento a reglas como la del "nullum crimen..." o la de "obligación de rechazar la demanda"- no puede ser, salvo argumentos muy finos, un sustituto válido de "respuesta correcta" (como pretende por ejemplo Fernando Atria 55 con las dos últimas reglas mencionadas). Porque aun si se admitiese que esta regla de Martínez es un sustituto válido surgen cuatro aspectos que hay que considerar de cara a una tesis que defienda la posibilidad de dilemas morales genuinos: Primero, que si existe tal regla jurídicamente estipulada carece de sentido la llamada "remisión" al dominio moral. Esto es así por cuanto dicha remisión -posibilitada por el tipo de términos empleados por ejemplo en una Constitución- sólo estaría conectada con

\footnotetext{
${ }^{55}$ Como se sabe, Atria defiende aquí dos tesis: la primera, que son posibles las lagunas normativas (nivel de los casos genéricos); la segunda, que, pese a la asunción anterior, siempre hay "respuesta correcta" para los casos "particulares". Véase Bulygin, Eugenio: “Los jueces ¿crean derecho?”, en Isonomía, Revista de Teoría y Filosofía del Derecho, 18, 2003, especialmente pp.23-24.
} 
la posible indeterminación del discurso moral pero ya no habría ningún mecanismo de solución de la moral que tuviese que ser "filtrado" por la dimensión institucional del derecho. Segundo, que aun si no se cancela esta remisión al dominio moral, se diluye por completo la posibilidad de dilemas morales genuinos desde que ya se columbra la existencia de una regla que "resuelve" el conflicto expresado por el dilema. Tercero, que esta regla solo puede "resolver" aquí en el sentido de que el derecho, por razones que fincan en su propio diseño, dispone de formas de encauzar demandas de prestación efectiva de justicia, pero no en el sentido de que el derecho pueda resolver efectiva o sustantivamente el dilema que se plantee. Cuarto, creo que las cosas son distintas si esta "regla" es estipulada en el contexto legislativo que si lo es en el contexto judicial, que es donde tiene lugar típicamente -no digo que exclusivamente- la ponderación. Esta propuesta me parece innecesaria en el contexto legislativo e imposible en el contexto judicial. "Innecesaria" en el contexto legislativo pues no es más que una fórmula redundante de decir que, en casos de dilema moral, da lo mismo tanto una como otra solución. Por supuesto que Martínez pretende evitar esto diciendo que esta "regla" estipulará en un sentido específico las soluciones; pero si es así, esto, lejos de despejar la objeción de Taurek fundada en principios de igualdad y dignidad de las personas, la refuerza pues siempre quedaría un resquicio para que las partes no favorecidas por la decisión se quejen. Por supuesto, Martínez puede declarar inexistente este resquicio, alegando que una vez que las cosas se han decidido legislativamente en un sentido determinado, las partes ya no pueden válidamente plantear quejas. Es posible que haya algo de verdad en esta respuesta eventual de Martínez, pero ella sólo podría ser plausible con elementos adicionales de teoría política, por ejemplo sosteniendo que las partes, sea cual sea su posición, tienen el deber de acatar aquello que se ha decidido en condiciones de participación deliberativa racional. Por ejemplo, el auxilio de las ideas de "posición original" y "velo de la ignorancia", debidamente explicitadas, podría apuntalar la legitimidad del intento de incluir, como parte del diseño 
institucional del derecho, reglas como ésta que él propugna. Pero este argumento no aparece en su trabajo. En lo que atañe al contexto judicial su propuesta me parece "imposible". Ello así por cuanto su mentada regla estipulativa sería aquí el producto de un acto de ponderación "in concreto" (lo que, siguiendo a Kant, llamé la "facultad de juzgar particulares"). Pretender ver en la ponderación de valores o principios inmersos en situación de genuino dilema, una solución "universalizable" me parece lisa y llanamente una locura por los siguientes motivos: primero, porque antes que nada hay que mostrar que en dilemas morales genuinos o dilemas jurídicos genuinos es posible activar la ponderación como método de "solución". Ello no resulta simple cuando se caracteriza a los dilemas morales como lo hace Martínez: en función de los rasgos de "equivalencia" e "incomparabilidad" de alternativas; dos rasgos que bloquean el paso inmediato a la ponderación. Segundo, porque aun si la ponderación fuese viable, su producto no puede ser anticipado -como ya sostuve antes- en la explicitación de las condiciones bajo las cuales triunfará o no la posición de A o B; concebir algo así choca con la idea común que se tiene de las situaciones de dilema. Tercero, porque si ya hubiese una ponderación que ex ante "ordenase jerárquicamente" valores, normas, principios, etc., no sería inteligible la idea de que, efectivamente, hay conflictos normativos, especialmente los dilemáticos. Pensar algo así, por ejemplo para el campo moral, es, desde luego, posible. Uno puede construir, a la Rawls, un "orden lexicográfico" de principios; pero, desde el momento en que se hace tal cosa, ya no puede hablarse de genuinas situaciones de dilema que puedan entablarse entre los principios que figuran en ese orden. Cuarto, porque, tal como vengo indicando, la ponderación que entraría en juego en situaciones "particulares" de dilema opera "in concreto", motivo por el cual, el eventual "ordenamiento de las pretensiones en conflicto" (cosa que solo sería posible desactivados los rasgos de equivalencia e incomparabilidad) establece jerarquías, "en principio", para "el caso en cuestión” (jerarquías "móviles”, en términos guastinianos).

El fracaso de la propuesta de Martínez, sin embargo, no lleva necesariamente a atarse de manos en materia de propuestas normativas. 
Estimo que hay una alternativa más plausible que se puede apoyar, en parte, en elementos de la propia argumentación de Martínez que él deja un tanto implícitos: me refiero al principio de igualdad que anida en su razonamiento.

Considero que mi propuesta, además, permitirá tender un puente entre los dilemas morales y los conflictos constitucionales, cuestión que a Martínez le interesa, aunque él realmente no establezca el puente más que de manera retórica. ${ }^{56}$

\section{Una propuesta normativa más aceptable}

Ante todo, adviértase que el argumento que subyace a la objeción de Taurek, objeción que Martínez hace propia, tiene raíz en el principio según el cual "las personas son merecedoras de igual respeto, dignidad y derechos". Pienso que es éste el principio del argumento de Martínez que puede proyectar mejor luz sobre la cuestión.

La cuestión a la que me refiero está circunscripta, por una parte, por el vínculo entre conflictos constitucionales y dilemas morales sobre el que Martínez llama la atención, por la otra, por el procedimiento de la ponderación desarrollado especialmente por los jueces como forma de "resolver" de alguna manera la contienda entre principios constitucionales.

Sobre esto último cabe subrayar dos aspectos: primero, que el contexto que aparece como relevante aquí es el judicial; segundo, que la idea de que la ponderación -como quiera que se la entienda- pueda "resolver" conflictos constitucionales que presuponen una versión de dilema moral es ininteligible desde que se admite que los dilemas morales

\footnotetext{
${ }^{56}$ Digo esto porque su mención de los "conflictos constitucionales" en el trabajo es bastante retórica en el sentido que no los pone a jugar de verdad con situaciones de dilema. Más bien, pese a su proclama, sus ejemplos más recurrentes en torno a la relevancia jurídica de los dilemas morales pasan por el tamiz del instituto de la "promesa".
} 
"no tienen resolución racional". A menos, claro está, que se extinga la idea de "no resolución racional" al precio de negar la posibilidad de dilemas morales genuinos y su relevancia "desafiante" tanto para el derecho como para la moral.

Mi propuesta normativa, que está inspirada en la obra Constitución y Conflicto de Robert Burt ${ }^{57}$, es que los jueces, particularmente aquellos que desarrollan su función en una Corte Suprema o Tribunal Constitucional, pueden desarrollar un trabajo intelectual que no suponga que todo el poder de decisión descansa en ellos. Más bien, mi punto es que estos jueces podrían -y deberían- desarrollar lo que Bickel llamó alguna vez el "método del coloquio" 58 entre la justicia y otras instituciones políticas, especialmente el Parlamento. Este método supone que los jueces no concentran todo el poder de decisión sino que hacen un trabajo que es completado por la discusión política en sede parlamentaria. Mi propuesta, como se verá pronto, sale al paso de las conocidas críticas que endilgan un carácter “contramayoritario" al poder judicial. Así, lo que propondré es un complejo mecanismo de decisión que vincula a la jurisdicción y a la política.

La propuesta en cuestión está fundada en casos reales de la experiencia judicial y política americana (aunque, pienso, esta experiencia puede extrapolarse a la mayoría de los países "occidentales"). De esta experiencia, me interesa específicamente un tipo de conflicto constitucional que bien podría llamarse "polar". Conflictos de esta índole hay muchos pero creo que la mención de casos como Brown v. Board Education y Roe v. Wade pueden ayudar a entender lo que tengo en mente.

Lo primero sobre lo que hay que meditar en conflictos de una complejidad como los mencionados arriba es que, cuestión ésta que interesa mucho a Martínez, "cuando la Corte declara que una parte tiene la razón

\footnotetext{
${ }^{57}$ Traducida por la Cátedra de Traducción de Interpretación IV de la Facultad de Derecho de la Universidad de Bs. As. a cargo de Gabriela Garrido de Ortells, Eudeba, Bs. As., 2000. ${ }^{58}$ Citado por Burt en nota 8 de p.487.
} 
y la otra no, que la primera ha ganado la contienda y que la otra resultó vencida, emite un pronunciamiento que tiende a eclipsar la obligación de respeto mutuo entre partes" ${ }^{59}$ ¿Cómo evitar que una parte -justificadamente- perciba que se encuentra a merced de la otra, tanto más cuando ambas partes tienen sobrados elementos como para saber que, de cada lado, sus pretensiones tienen equivalente legitimidad?

Siguiendo el análisis efectuado por Burt, mi respuesta es que los jueces tienen que desplegar una serie de "técnicas jurídicas específicas" que presupongan el impulso de un proceso legislativo cuya consecuencia sea que "ninguna de las partes pueda declararse completamente ganadora" ${ }^{60}$ Lo que está en danza aquí no es ni más ni menos que el requisito de igualdad que subyace a las preocupaciones de Taurek. La idea es que la igualdad sigue vigente incluso "cuando las partes no queden satisfechas en igual medida". ${ }^{61}$

No es necesario que me extienda en este lugar con una descripción detallada de estas técnicas ${ }^{62}$. Pero diría que el "común denominador" a todas está dado por la idea de que es preciso fomentar procesos deliberativos racionales en sede legislativa en diálogo con las instituciones jurisdiccionales. Cabe apuntar que las diversas técnicas que emplean los jueces deberían perseguir la finalidad según la cual, en conflictos polares

${ }^{59}$ Burt, Robert: Constitución y Conflicto, op.cit., p. 478.

${ }^{60}$ Burt, Robert: Constitución y Conflicto, op.cit., p. 485.

${ }^{61}$ Burt, Robert: Constitución y Conflicto, op.cit., p. 495.

${ }^{62}$ Entre otras, estas técnicas, analizadas con detalle y con abundantes ejemplos por Burt, son las siguientes: i) La técnica de no avocarse a cuestiones de fondo cuando éstas son "vagamente" formuladas por la ley de que se trate; ii) la técnica que aplica el llamado "principio de madurez" según la cual la Corte rechaza todo pedido que no demuestre que los contrincantes se avienen a respetarse mutuamente; iii) la técnica del "análisis intermedio" que combina interpretación "superficial" de las cláusulas legales y/o constitucionales con un examen "profundo", etc. Cfr. Burt, Robert: Constitución y Conflicto, op.cit., especialmente pp. 484-492. 
como los mencionados, ninguna parte pueda considerarse absolutamente ganadora y la otra absolutamente perdedora.

En el presente contexto vale la pena aclarar que las técnicas judiciales en cuestión podrían ser moldeadas por dos tipos de intervenciones de los jueces: o bien que éstos declaren lisa y llanamente la cuestión a resolver como "política" y por ende "no judiciable" o bien que se avoquen al tratamiento de la misma pero empujando las cosas hacia un proceso legislativo como el descrito anteriormente -si son dilemáticos- sean 'resueltos' sin más. Más bien, supone que los jueces deben ser conscientes de su poder y que hay cuestiones que, por su importancia, deben ingresar a una agenda de debate más plural que abrace también a la política. Esto no necesariamente debe ser fuente de temor para quienes ven en un poder judiciario exclusivo la protección del "coto vedado" de "derechos individuales" que un Ulises “desatado" podría desbaratar. Mi idea es que, con ciertos límites racionales, la deliberación sobre estas grandes cuestiones debería ser posible.

Desde luego, lo que acabo de observar podría hacer pensar que, en el fondo, estoy en el bando de los que niegan la existencia de dilemas morales genuinos si por esto se entiende conflictos "no simples" o "no resolubles racionalmente". Pero no es así. Entiendo que la razón tiene límites y esto se testifica por la presencia posible de dilemas morales genuinos. Sin embargo, esta presencia puede ser reducida en muchos casos y reencauzada por procedimientos complejos -judiciario-político como el que describí- que hagan de la deliberación un arma para equilibrar pretensiones y no permitir que una parte se quede con todo. Esto no "resuelve" el conflicto en lo sustancial, pero sí supone que las partes en contienda suscriben lo que Berlin ${ }^{63}$ llama "compromisos básicos"; compromisos que, mientras más amplios sean, más perdurables pueden resultar.

${ }^{63}$ Berlin, Isaiah: "Persecución del ideal”, en El Fuste Torcido de la Humanidad. Capítulos de historia de las ideas, Traducción de José Manuel Álvarez Flóres, Edición a cargo de Henry Hardy y Prólogo de Salvador Giner, Ediciones Península, Barcelona, 1998, pp. 35; 37. 
Pero lo que acabo de describir no puede ser descontextualizado de ciertas teorías filosóficas y de ciertos momentos históricos y sociales. Por ejemplo, una teoría como la de las virtudes de Aristóteles, que no acepta dilemas morales genuinos, no está construida sobre el vacío sino sobre un momento histórico especial vivido por la polis griega. Parte de lo que piensa Aristóteles ya estaba contenido en la "Oración Fúnebre" con que Pericles ${ }^{64}$ muestra implícitamente la futilidad de los falsos dilemas que, según Castoriadis, envenenan la filosofía política moderna y que oponen, por ejemplo, al "individuo" contra la "sociedad civil", la "sociedad civil" contra el "estado".

Con esto quiero insinuar que la afirmación o negación de dilemas morales no puede desgajarse de un momento histórico y de una tradición filosófica. La idea, muy conocida, es que las tradiciones pueden generar "problemas" que no puedan enfrentar adecuadamente. Por ejemplo, para la tradición dialéctica de Hegel las oposiciones, generadoras de dilema, entre individuo y sociedad civil y entre sociedad civil y estado configuran sólo momentos que habrán de disolverse con la consagración de un estado de derecho entendido como "forma racional" de la existencia humana.

Concedo desde ya que mis sugerencias sobre el papel de los "momentos históricos" y su relación con las teorías filosóficas levantan cuestiones intrincadas. ¿Es compatible el llamado "análisis filosófico” con cuestiones de génesis histórica de valores, conflictos de valores y teorías específicas sobre ellos? Si fuera compatible, ¿de qué tipo de historia se trata? ¿Cómo se pueden relacionar en términos conceptualmente sugestivos cuestiones de "génesis" y "validación" de teorías filosóficas? Estas son solamente algunas de las preguntas posibles que uno se puede plantear. Desafortunadamente, las respuestas para ellas, dado el espacio que me he prometido respetar aquí, no podrán ser desarrolladas en el presente trabajo.

${ }^{64}$ Ver Castoriadis, Cornelius: "La polis griega y la creación de la democracia”, en Los dominios del hombre, op.cit., pp. 130-131. 


\section{Recapitulación}

En este trabajo he realizado dos tareas: i) observar críticamente lo que he considerado como aspectos deficitarios del planteo de David Martínez con relación a los dilemas morales y su vínculo con el derecho, particularmente los conflictos constitucionales; ii) sugerir vías alternativas para ver las cuestiones involucradas de un modo más apropiado.

Las tareas señaladas se han movido en torno a las dos pretensiones esgrimidas por Martínez: la conceptual y la normativa. Entre otros señalamientos, con respecto a la primera pretensión: a) he sostenido que él no logra distinguir adecuadamente conflictos normativos simpliciter de dilemas morales; b) observé que deja de lado injustificadamente hipótesis importantes de relevancia jurídica de dilemas morales; c) dije que confía demasiado en una imprecisa "remisión" a la "moral" y que, en consecuencia, no se ocupa de una categoría fértil como la de "dilemas jurídicos"; d) mantuve que no establecía un puente verdaderamente efectivo entre conflictos constitucionales y dilemas morales; e) puse en duda que la estipulación sea un recurso válido, salvo que no quede otra salida, para enfrentar problemas filosóficos de la complejidad de los dilemas morales; f) defendí una caracterización de dilema moral en términos del reconocido enfoque de los "casos trágicos", intentando anticipar posibles réplicas del autor criticado, y g) sugerí que para una clarificación conceptual más penetrante de los dilemas morales podría ser una buena estrategia distinguir entre dilemas morales trágicos y no trágicos, aún si los segundos son los menos problemáticos e interesantes para la filosofía moral.

Con respecto a la segunda pretensión he mantenido que ella es la parte más atractiva del trabajo de Martínez pero su dirección no es consistente con las pretensiones de su trabajo y, aun si lo fuera, sería inviable. Seguidamente, sugerí una propuesta normativa diferente y, según creo, más defendible. Para esto hice en parte pié en algunos sugestivos argumentos de Martínez.

Solo me resta agradecerle a Martínez profundamente por su trabajo pues el mismo ha sido fuente de inspiración para mí y me ha 
obligado a pensar sobre aspectos que no vislumbraba en forma consciente. Creo que en una discusión filosófica nadie puede arrogarse la palabra exclusiva y celebro la oportunidad que nos brinda Discusiones a los distintos participantes de cooperar en el análisis de los problemas filosóficos y de acercar tesis diferentes de cuyo choque cabe esperar una saludable corrección mutua.

Pienso, por último, que David Martínez cuenta con muchas flechas en su carcaj para completar adecuadamente esta discusión con su réplica. 